\title{
A Techno-Business Platform to Improve Customer Experience Following the Brand Crisis Recovery: A B2B Perspective
}

\author{
Rajat Kumar Behera' ${ }^{1}$ (D) Pradip Kumar Bala ${ }^{2}$ Nripendra P. Rana ${ }^{3} \cdot$ Hatice Kizgin ${ }^{4}$
}

Accepted: 7 December 2021 / Published online: 15 January 2022

(c) The Author(s), under exclusive licence to Springer Science+Business Media, LLC, part of Springer Nature 2021

\begin{abstract}
A platform is a business model that allows business-to-business (B2B) participants to connect, interacts, create and exchange value. B2B exploits social media for brand building and branding is vulnerable to attacks, which leads to a brand crisis. B2B should characterise such crisis and respond proportionally to avert damage to social listening (SL). To diminish damages, the solution is to measure customer experience (CX), especially in a crisis situation. The study proposes an analytics-enabled customer experience $(\mathrm{AeCX})$ platform for emotion detection in social media and measures $\mathrm{CX}$ after recovering from such crisis, by exploring recovery time objective (RTO), recovery point objective (RPO), techno-business features (TBF), SL and perceived risk (PR). A quantitative research methodology is used on primary data collected from 302 B2B participants. The study reveals improvement in CX and the results provide evidence that social media channels and the TBF of AeCX have become important.
\end{abstract}

Keywords Post brand crisis $\cdot$ Techno-business platform $\cdot$ Customer experience $\cdot$ Social media $\cdot$ B2B

\section{Introduction}

Rajat Kumar Behera

rajat_behera@yahoo.com

Pradip Kumar Bala

pkbala@iimranchi.ac.in

Nripendra P. Rana

nrananp@gmail.com

Hatice Kizgin

kizgin.hatice@gmail.com

1 School of Computer Engineering, Kalinga Institute of Industrial Technology (KIIT) Deemed to be University, KIIT Road, Patia, Bhubaneswar, Odisha 751024, India

2 Information Systems and Business Analytics, Indian Institute of Management Ranchi, Suchana Bhawan, 5th Floor, Audrey House Campus, Meur's Road, Ranchi, Jharkhand 834008, India

3 College of Business and Economics, Qatar University, P.O. Box 2713, Doha, Qatar

4 Faculty of Behavioural, Management and Social Sciences, University of Twente, P.O. Box 217, 7500AE, Enschede, Netherlands

Larger spending in the advertisement to generate awareness and create a positive brand image is an efficient marketing strategy for B2B businesses (Guenther and Guenther, 2020). At present, B2B businesses are facing a variety of challenges, which can be tackled by increased advertising (Guenther and Guenther, 2020). First, because of strong global competition differentiating B2B offerings with practical advantages and price has become increasingly difficult (Leek and Christodoulides, 2011; Lindgreen et al., 2010). Second, the research source on the effectiveness of sales forces suggests that businesses have effectively depleted the resources available to increase revenue using a different form of communication (Claro and Kamakura, 2017; Chan et al., 2014). Social networking platforms have been widely used as marketing tools powered by the ability to meet and engage millions of customers with brand-related content and conversations (Schivinski and Dabrowski, 2016) as social media has a higher predictive value than traditional online media (Luo et al., 2013). Social media advertisements facilitate the overvalued marketing tool for B2B businesses and it (Kushwaha and Kar, 2021) is one way to promote a marketing product. There is a lot of useful information on social media (Duan and Da, 2021) and can offer B2B marketers 
the unique opportunities in the complex decision-making process to improve customer experience following the brand crisis recovery.

Good corporate reputations build cross-buying intentions by enhancing the anticipated level of service, reducing knowledge costs, confidence and affective commitment (Jeng 2008, 2011). In modern times, businesses need to understand the real position of their products on the web as more and more customers rely on online opinions when making buying decisions (Kaiser et al., 2011; Forman et al., 2008). Online product reviews and reviewer-related data are considered as one of the most significant knowledge base systems that derive from social media (Sikora and Chauhan, 2012). Although social media empowers businesses to increase traffic, reach and lead, however, if not properly used, this can damage the brand image. Unfortunately, social media suffers from non-friendly participation bodies (Zhang and Gupta, 2018). Digital marketers of the buyer organisation or customers can blow off the issue into a social media brand crisis (thereafter crisis symbolise brand crisis), therefore action is required for the seller to determine the level of crisis and respond proportionally. Accordingly, businesses or brands are faced with crises and have negative publicity and symbolic consequences for the business (Yannopoulou et al., 2011).

Product-related crises, which often occupy the public and media room, are viewed as distinct, well-publicised events in which products are found to be defective or unsafe (Siomkos and Kurzbard, 1994). Defective products, design errors, defective production, product recalls and even marketing errors may cause a crisis, meaning the creation and distribution of problematic brand images to a wide audience, which, as many researchers have suggested, has profound implications for brand equity and brand trust (Dawar and Pillutla, 2000). Product-related crises are a distinct form of brand-related crisis that often occur at the abstract association stage and cause negative publicity (Dawar and Lei, 2009) and we argue that negative publicity via social media is the best piece of negative word of mouth promotion. Also, the growing complexity of products, combined with more demanding buyers make product-related crises much more frequent (Yannopoulou et al., 2011; Klein and Dawar, 2004; Birch, 1994; Patterson, 1993). Also, brand trust is very fragile, because it is dependent on the expectations of consumers. It leaves brand trust vulnerable to significant and unexpected changes due to factors beyond the control of the management (Yannopoulou et al., 2011). While handling the brand crisis, the negative effect might damage the business brand. According to Knight and Pretty (2001), the price of the post-crisis share declines by as much as 15 percent a year later. The acute phase of crisis communication is well documented for customers (Dawar and Lei, 2009; Dutta and Pullig, 2011), but crisis recovery and customer experience are less understood. Scholars recognise that B2B action is required to shape the tarnished reputation and rebuild the brand equity.

Several B2B digital marketing activities such as customer lifetime values and prospecting marketing campaigns can be handled with the advances in computer technology (Hausman et al., 2005) and an analytics-enabled business platform is the solution enabler. The proposed AeCX is the unified techno-business (analytics-enabled) platform to measure $\mathrm{CX}$ of $\mathrm{B} 2 \mathrm{~B}$ after recovering from the crisis. The platform is intended for emotion detection (ED) in social media at different stages of the post brand crisis recovery process. ED is a form of sentiment analysis that involves extracting and analysing emotions (Acheampong et al., 2020). In the event of a such crisis, the customers dislike the brand so much that they not only ignore it but also openly declare their dislike for it (Elsbach and Bhattacharya, 2001; Wolter et al., 2016). When spread widely in social media, negative word of mouth (NWOM) can quickly turn into an online firestorm, releasing massive amounts of NWOM (Pfeffer et al., 2014) and potentially cause significant brand damage (Ruppel and Einwiller, 2021). We argue that in such events, gone over the days when B2B could extract insights out of customer's emotion from social media without the presence of an analytics-enabled platform, hence the importance of an analytics-enabled platform $(\mathrm{AeCX})$ is the most pressing need. By adopting AeCX, B2B can (i) make data-driven decisions across teams and foster innovation, (ii) uncover trustworthy insights in a self-service manner, (iii) speed up time to insights, (iv) improve mobility, performance and quality (v) allow for efficient communication and automated business processes that lower business costs.

The existing research in the B2B crisis has focused on the financial crisis (Grewal and Tansuhaj, 2001), service crisis (Baliga et al., 2021), product crisis (Yuan et al., 2020) and brand crisis (Beverland et al., 2007) amplified through conventional media and focused on how organisations stake social media into account in crisis communication. Existing research also focused on the barriers in the adoption of social media due to brand awareness in B2B (Dwivedi et al., 2021), challenges of social media in B2B small-andmedium enterprises context (Iannacci et al., 2020), integration of cognitive chatbot with social media for continuous improvement of personalised contextual customer service in B2B context (Behera et al., 2021) and lack of a clear understanding of social media-enabled service co-creation in B2B non-profit organisations (Namisango et al., 2021). Compared to conventional media, the degree to which social media affects the brand attitude in the event of a brand crisis is larger (Pace et al., 2017). By considering SL, none of the studies discussed recovery and CX strategy in the event of a post crisis by taking full advantage of the digital age and social media. SL whose mainstream is ED provides avenues 
for brands to trace, evaluate and respond to social media conversations, which is the crucial component of customer research. However, a little is known about the specific role of CX using the techno-business platform (Wells, 2018; Zoric and Braek, 2011). This research gap is addressed by presenting a techno-business platform to recover after such crisis with the goal of a growth-oriented business outlook for B2B participants.

A phenomenon has been observed that providing timely and consistent CX during a crisis bolsters buyer's confidence by allowing them to know what to expect and trust from the seller. Therefore based on this and recent advancement in information technology, the following research questions (RQs) are addressed:

RQ1. How do recovery time objective and recovery point objective leverage social media coverage to regain positive public sentiment?

RQ2. How do the social listening and the techno-business platform improve customer experience?

RQ3. How perceived risk moderates the association of techno-business features towards customer experience?

The remaining sections of this research are structured as follows: The theoretical background is presented in Section 2. The research methodology is described in Section 3. Section 4 contains the results and findings, while Section 5 includes the discussion. Finally, Section 6 concludes the study.

\section{Theoretical Background, Conceptual Model and Hypotheses Development}

The theoretical background is based on an extensive review of the literature. We first discuss the literature on the business model, social emotion detection, techno-business platform, theoretical model and then present a discussion of the hypotheses.

\subsection{Business Model}

We are proposing a five-stage business model for post brand crisis recovery, grounded on (Iabc, 2018). These stages are (i) Recognise, (ii) Recalibrate, (iii) Restore, (iv) Redirect and (v) Reinvigorate. The proposed business model is deemed appropriate for B2B and helps sellers to repair a tarnished reputation in social media. Also, it manages recovery expectations at all levels of the organisation and across all buyers' groups. The existing business model (1) is for the evaluation of the marketing strategy of B2B (Muzellec et al., 2015) and (2) is to generate data-centric web services (Baghdadi, 2004). Muzellec et al. (2015) propose a blueprint for the evolution of two-sided Internet businesses' marketing strategies and business models in which intermediaries on the Internet are seen as resource integrators, bringing together customers and business partners in a value-creation process. Baghdadi (2004) proposes a business model with several interfaced abstraction levels as a framework for generating data-centric web services, in which a time/space constraint known as factual dependency is used to aggregate attributes representing business objects and communication artifacts as defined in the highest abstraction level of a business model. In summary, both models have shortcomings as they were not developed for social media and were not targeted in postbrand crises. Each stage of the proposed business model is discussed below.

Recognise: There is a need to recognise the events that end the crisis. Well-prepared organisations understand that a crisis has the potential not only to impact themselves and their products but also the broadest variety of potential stakeholders including customers, suppliers and representatives of the general community (Pearson and Mitroff, 1993). Recognising the human capacity to identify and correct mistakes are the foundation for creating successful crisis management (Comfort, 2007). Following the above studies, we argue that indication from social media includes the change in topics coverage based on tonality, volume, interaction like shares, retweets, comments, word of mouth (WoM) and conversation rate. In summary, the stage recognises that the acute crisis has stopped and time for a transition to recovery mode.

Recalibrate: Recalibration of a realistic recovery plan begins with an awareness of the crisis itself and the relevant problems that arises through social media reporting. Following the conceptualisation of brand associations, the details in the crisis are initially analysed at the level of benefit associations to arrive at a summary assessment of the crisis, which requires an assessment of the brand's effect or severity (Dawar and Lei, 2009). Following the above study, we argue that understanding the severity of the crisis usually includes quantifying changes in corporate image, evaluating variances in the attitudes of stakeholders towards the business, and assessing the impact on the brand, executives, or particular individual deemed responsible for the incident. Regulatory bodies that supervise a product or service are also key stakeholders to be considered in assessing the impact. In summary, this stage recalibrates the damage to the brand and business. Restore: It is equipped with a strong understanding of the difference between the credibility of pre and post crisis and the next stage calls for a plan to be formulated that will take the business on a path towards normalisation. The literature on crisis communication focuses on crisis management (Charlebois and Elliott, 2009) and how 
stakeholders (Coombs and Holladay, 2012) respond to different forms of crisis and crisis response strategies (Coombs, 2007). The audience, who receives information about the crisis through social media and has a positive outlook towards the crisis-impacted issue, responds more negatively to the brand than the audience that is exposed to conventional mass media (Pace et al., 2017). Following the above study, we argue that there should be an offsetting system feature explicitly designed to restore the damage for any credibility attribute, which is seriously damaged during such crisis. In summary, in this stage outreach strategies for key stakeholders are articulated to restore the situation.

Redirect: Looking for ways to improve is good as negative self-talk is destructive and ineffective. To moderate the relationship between dimensions of justice and attitudinal responses, reputation was empirically tested and the findings suggest that dimensions of justice affected happiness and confidence, with distributive justice providing the greatest relative impact and perceived justice producing positive WoM and intentions to repurchase (Ding et al., 2015). A business with a stronger corporate image, the impact on recovery satisfaction and trust in perceived dimensions of injustice were greater (Ding et al., 2015). Following the above study, we argue that reputation management activity needs paradigm shifts from reactive responses to constructive programming. In summary, in this stage, the negative dialogue is redirected and preempt with positive programming.

Reinvigorate: When a brand starts to stagnate, B2B organisations need to reinvigorate the values that inspired the business in the first place. To reinvigorate the brand, the decision should be taken to reorganise the product lines, and house equipment and apparel (Beverland and Ewing, 2005). Following the above study, we argue that B2B business either support the core values eroded by the crisis or introduces new values embraced as a result of the crisis. In the era of social media, transparency emerged as the defining characteristic of communication, so B2B business must maintain an open dialogue through social media. Employee and leadership stakeholders need to understand what happened and why, accept the corrective steps needed and model the behaviours that show the corporate brand delivers on its promise. In summary, this stage gives new synergy to brand values and relationships.

\subsection{Social Emotion Detection}

With the rise of social media and the availability of product reviews, statistical polling data and other user-generated content, an ever-increasing amount of valuable information about user opinions and emotions is being collected and processed online (Bosco et al., 2013; Poria et al., 2013). The rapid growth of social media has been a huge boon for emotional communication through blogs, microblogs/ tweets, instant messaging tools, news portals, etc. (Rao et al., 2014b). Social emotion detection aims to predict the emotions evoked by news stories, tweets and other social media posts (Lei et al., 2014). Opinion summarisation (Ku et al., 2006) and sentiment retrieval (Eguchi and Lavrenko, 2006) are the two applications of social emotion detection that have gotten a lot of attention from researchers (Cambria and White, 2014; Wang et al., 2011). We argue that B2B products and brands are more nuanced and realistic than flashy, therefore B2B value logic and reason over emotions in the event of post crisis.

Constructing a classification model is a common goal of sentiment analysis (Xie et al., 2021). There are two types of approaches for social emotion detection: discriminativemodel based and topic-model based (Tang et al., 2019). Many discriminative-model based methods have been proposed by turning emotion detection into a classification problem (Poria et al., 2015, 2016), such as the logistic regression model with emotion dependence (Quan et al., 2015) and the social opinion mining model based on K-Nearest Neighbour (Li et al., 2017). However, such approaches fail to disclose the latent topic information needed to understand how emotions are evoked (Tang et al., 2019) and to address such problems, topic-model based approaches have been widely used for social emotion detection (Rao, 2015; Rao et al., 2014a). The Emotion-Topic Model (ETM) (Bao et al., 2009), Sentiment Latent Topic Model (SLTM) (Rao et al., 2014b) and Contextual Sentiment Topic Model (CSTM) (Rao, 2015) are topic-model based and detect emotion or polarity bearing topics. Such models are based on the bag-of-words assumption (Tang et al., 2019). We argue the bag-of-words have limitations such as it results in a high-dimensional feature vector owing to the broad size of the vocabulary, it assumes that all words are independent of each other and as there is nonzero value in the dimensions corresponding to words that appear in the sentence, this results in highly sparse vectors. Hence, we propose a hidden Topic Transition (TET) model (Tang et al., 2019) that is used to describe emotion and topic transitions at the same time.

Each sentence is treated as a basic unit by TET and all words in the same sentence are considered to have the same topic and emotion labels. To avoid the document-level bagof-words assumption, the topic transition and emotion transition in successive sentences are modelled using a hidden Markov model and learned from data (Tang et al., 2019). TET can detect emotions at both the text and sentence levels. Tang et al. (2019) experimented with the two publicly available corpora, a news dataset and a blog dataset, and it outperforms state-of-the-art approaches for document-level and sentence-level emotion detection, as well as underlying 
topics that elicit the corresponding emotions. We argue, after recovering from the crisis, B2B should integrate data-driven analytics with social emotion to improve customer experience. In this context, emotional analytics play a pivotal role by identifying and analysing the full human emotional spectrum, including mood, attitude, and emotional continuum, concerning their brand perception and preferences. Customers' specific preferences can be identified using emotional analytics, allowing brands to develop a tailored and personalized experience for them. In addition, brands may use emotional analytics to monitor customer's emotional responses to various campaigns or advertising, as well as to recognise and replicate popular elements in future campaigns. Voice emotion analytics can be utilised to understand the customer feeling from the publicly posted audios or videos on social media.

Today, B2B is subjected to new expectations, competitors, channels, threats and opportunities. After recovering from the crisis and maximising customer satisfaction, B2B leaders and C-suites must make decisions based on a thorough understanding of customer's social emotions. The required time-bound actionable insight and probabilistic recommendation is something that descriptive, diagnostic, predictive, prescriptive and cognitive analytics can help B2B if adapted and adopted.

\subsection{AeCX Platform}

Businesses can use analytics-enabled business platform to absorb, organise, identify and analyse data to uncover actionable insights that can help to enhance decision-making, inform business strategy after recovering from the crisis. The literature has proposed analytics enabled platforms catering to different needs. Rabhi et al. (2021) presented an information technology platform for data sharing amongst various analytics models, with the knowledge accumulated in the platform can assist future data analysts in the organisation. One major drawback is that analysts would be unable to create and execute custom analytics scenarios as needed. Bauer et al. (2021) proposed a large-scale enterprise data analytics platform that allows hundreds of globally distributed teams across the company to analyse a wide range of corporate data assets, including sales, marketing, and customer information, as well as data from less traditional sources like weather, news, and social media. The study was not confined to brand crisis and was lacking aspect of prescriptive and cognitive analytics. Farrokhi et al. (2020) proposed a critical event detection analysis (CEDA) for detecting critical events in $\mathrm{B} 2 \mathrm{~B}$, which is a sentimental big data analytics approach. The study was limited to organisational crises and did not address external crises and the crises related to the brand. Cortez and Johnston (2020) proposed a platform model to describe how the firms can manage coronavirus crises for B2B with four intertwined areas, namely digital transformation, decision-making processes, leadership, the combination of emotions and stress. The study was associated with coronavirus and did not cover crisis related to social media and brands. Based on the above discussion, it can be concluded that none of the studies has categorically proposed techno-business platform to improve customer experience following the crisis recovery from the perspective of B2B. Moreover, none of the studies has considered a business recovery model following brand crisis. Hence, there is a need to design an analytics-based business platform to improve customer experience following the crisis recovery.

A multifaceted and largely open challenge is the convergence of business platforms with technology (Porra, 2000). Therefore, for current and future systems tolerate the usual turbulence of technology and the business climate, the survivable techno-business platform is important (Caruso and Umar, 2004). Post to the event of a crisis in social media, there is an ever-growing demand to maintain steady customer satisfaction by fulfilling the demand of the buyers. Hence, the radical information technology innovation with technical and business features is required to monitor the voice of buyers and prospects in social media and ensure a positive buyer experience to leave positive reviews that help the sellers to retain revenue and attract prospects. The technical and business feature (TBF) sets the tone for improved customer experience and is one of the constructs in the proposed research model. The proposed techno-business (AeCX) platform is depicted in Fig. 1 and is adapted from Zutshi and Grilo (2019).

Zutshi and Grilo (2019) proposed a component based digital platform that is customer facing platform, empowers businesses, ranges from simple to complex marketplace and interfaces with social media systems. However, it is not exclusively designed to meet the context of this study and hence the proposed AeCX platform has adapted the components such as the business layer, user interaction layer, integration layer and data layer from it. The operative layer and functional layer component are exclusively added considering the context of this study. Each of the layers performs a specific role within the platform and carries unique responsibilities and further elaborated below.

\subsubsection{Business Layer Component}

In this layer, business models are developed, which encourages ecosystem actors to collaborate (Zutshi and Grilo, 2019). The concept of business models as a "theory of a business" is not new (Drucker, 2012) and academic scholars have become interested in business model research (Joyce and Paquin, 2016). Despite the progress in academic research on business models, scholars still do not agree on 


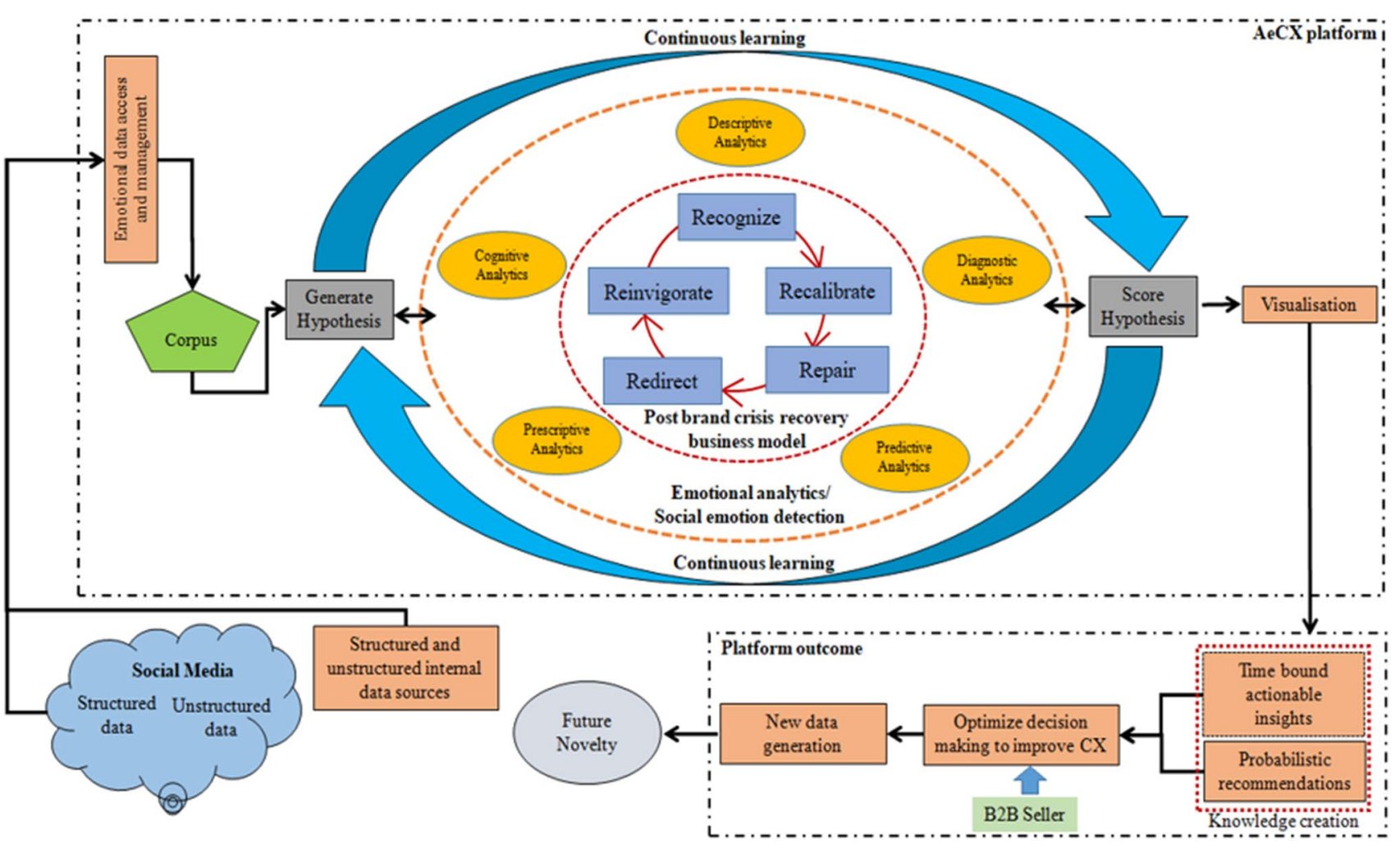

Fig. 1 Techno-business AeCX platform (Adapted from Zutshi and Grilo, 2019)

what a business model is (Zott et al., 2011), therefore the business model includes the interconnected stages of recognise, recalibrate, restore, redirect and reinvigorate emphasizing post crisis recovery. In each stage, a continuous learning process (a part of operative layer) is carried out until response satisfaction is achieved. A business model enables a business to build value in collaboration with its partners while simultaneously sharing a portion of that value (Zott and Amit, 2010) and thus, justify the inclusion of the component in the proposed platform.

\subsubsection{User Interaction Layer Component}

In this layer, producers and consumers interact with the platform using a variety of human-machine interfaces (Zutshi and Grilo, 2019), such as visualisation. Human-machine interaction is a tool-mediated activity which is facilitated by interactivity, contextualisation and personalisation capabilities and user experiences such as sense of control, motivation fulfilment and apparent comprehension are shaped by such capabilities, which influence how willing people are to interact with systems (Sun, 2020). In recent years, there has been a significant increase in the number of apps that can interact with humans and understanding human behaviour is a key aspect in their success (Feng et al., 2020). Therefore, the visualisation component enabled B2B participants to gain more quickly and the confident insights from all forms of emotional data, as well as improve decision-making to generate new data, resulting in future innovation. Brand volume is one of the best measures of impending crisis. If a graph renders differently than expected, the visualisation can alert with an early warning score. The visualisation also helps to show how the trending topics are evolving over time and depict positive vs. negative topics. There are other factors B2B needs to consider, but in the interest of crisis brevity like (i) who is driving the conversation in social media, what is the effect, (ii) is this isolated or triggering in multiple social media accounts, (iii) adverse impact to sales, operations, finance, etc. (iv) real-time brand propositions, etc. When communicating user-relevant data, people's ability to grasp visualisations should be a top priority (Herrmann et al. 2021) and temporal analysis is supported by data visualisation (Gupta et al., 2018). The above discussion justifies the inclusion of the component in the proposed platform.

\subsubsection{Integration Layer Component}

Today's digital platforms are not stand-alone pieces of software and instead, they interact with a variety of others (Zutshi and Grilo, 2019), such as emotional data access and management. It is the main interface between the AeCX and social media/internal data sources. There has 
been an increased demand for fundamental integration requirements and its main function is to enable information technology to improve the effectiveness and efficiency of corporate operations (Hung et al., 2007). Because of the societal implications, product quality and safety information have received a lot of attention, which is feasible with information integration (Xu et al., 2019). Therefore, all emotional data from external or internal sources to be imported must come through business rule processes. Examples of business rules are the data adoption (i) with pre-approved language, (ii) on how a B2B acknowledges a crisis in social media, (iii) on designated staff who take ownership and work on the crisis response, (iv) on response timeline, (v) on the attended and unattended crisis, and (vi) on crisis severity/priority, etc. It additionally performs feature extraction by identifying required attributes for the analysis and also to abstract data for further computation. People can easily convey their emotions through social media, and utilise these platforms to express their feelings about how they felt about a crisis circumstance, how they reacted to a crisis response decision, etc. (Sasidhar et al., 2020) and hence, emotional analytic/ social emotion detection play a vital role to understand the person's mood and attitude, and thus, justify the inclusion of the component in the proposed platform.

\subsubsection{Data Layer Component}

Volumes of data are stored on digital systems, including data created by ongoing user engagement and the data layer is responsible for the storage systems (Zutshi and Grilo, 2019), such as corpus. The corpus is a knowledge base, used to answer questions, uncover new patterns or relationships and provide new insights related to the crisis. The base corpus must be created and the data must be ingested before launching the platform. The data layer addresses the growing relevance of data, which has the potential to become one of the most important value propositions in the future (Püschel et al., 2016). In the storage systems, information management and processing has an impact on knowledge discovery (Diamantini et al., 2013). Therefore, the content of this base corpus constrains the types of post crisis problems that can be solved and the social emotional data within the corpus has a significant impact on the efficiency of the platform. Data policies for protection, security and compliance are out of the scope of this study. A corpus is the machine-readable representation of the complete record of brand crisis topic and a platform leverages it to make inferences and observations about the crisis from all varieties, volumes and velocity of data, and thus, justify the inclusion of the component in the proposed platform.

\subsubsection{Operative Layer Component}

This layer includes operative elements such as a continuous learning to generate and score the hypothesis for the continuous improvement of the platform. Seeking and using feedback, defining growth goals, participating in developmental activities and tracking progress are all examples of continuous improvement (London and Smither, 1999). Given the complexity of the knowledge, there is an obvious need for continuous, adaptable and efficient learning (Giannakos et al., 2021). Therefore, continuous learning is based on a hypothesis, which has supported facts or information to explain the causal relationship related to the crisis. Hypotheses are generated based on post crisis facts that made it possible to answer questions about the user experience that looked at for plausible explanations. Once the hypotheses are generated, the next step is to evaluate or score these hypotheses based on the evidence in the corpus and then to update the corpus and report the findings. Nonetheless, scoring or evaluating hypotheses is a process of applying statistical methods to the pairs of hypothesis-evidence to give the hypothesis a confidence level. The hypotheses generation/ scoring loop can continue until the B2B seller business is satisfied with the response or until all options are assessed. In coping with the crisis, Jack Welch suggested considering the five hypotheses (Jianying, 2012) and we argue that such hypotheses apply to the crisis in $\mathrm{B} 2 \mathrm{~B}$ and require continuous learning. First, considering that the crisis is worse than it appears at first glance and what is expected. The majority of the time crises last longer, expands on a wider scale and is more difficult to manage. As a result, at the start of the crisis, B2B should plan for the worst and then fix it promptly to improve CX. Second, B2B is the only way to reveal the facts about a crisis to the concerned public in social media. If they do not do so, others will and it will become much more difficult to handle and manage. During these times, crisis and recovery should be informed to the concerned public promptly to improve $\mathrm{CX}$. Third, B2B should describe the crisis in the most hostile way in social media, including the measures it took to improve CX over a period of time. Fourth, assuming that customers can change and a crisis will not truly end if B2B does not pay the price. This is not simple, but without it, B2B would be unable to move forward. The looming crisis in brand value and the avoidance strategy should be devised promptly to improve CX. Fifth, assuming that B2B will survive the crisis and such a test will make them even stronger. As a result, B2B must boost confidence promptly to improve $\mathrm{CX}$. These hypotheses are the core which B2B has to adopt and others can be adopted depending on the crisis severity, type, need, etc. Creating and validating hypotheses is necessary for the generation of multiple answers (Gudivada et al., 2016) and thus, justify the inclusion of the component in the proposed platform. 


\subsubsection{Functional Layer Component}

This layer includes functional elements such as analytics. The broad acceptance of the fermium business model as well as the advent of cost-effective analytics solutions has made analytics more accessible (Mäntymäki et al., 2020). Many firms have embraced analytics to make data-driven choices and improve daily operations as a result of the influx of data in various forms (Zolbanin et al., 2019) and B2B is not an exception (Hallikainen et al., 2020; Wang et al., 2020). Business analytics such as descriptive, predictive and prescriptive analytics are the most significant areas for better decision making as the amount of data grows exponentially (Song et al., 2014). Diagnostic analytics helps in identifying the factors that contribute to actual performance (Shao et al., 2014). By evaluating multiple heterogeneous data sources using cognitive models that the human brain employs, cognitive analytics uses the cognitive computing environment to provide actionable insights (Gudivada et al., 2016). Therefore, the emotional analytics include descriptive analytics, diagnostics analytics, predictive analytics, prescriptive analytics and cognitive analytics. Such a diversified emotional analytical model provides insights into the data to guide decision-making. The descriptive analytics assist to comprehend the relationship between emotions and social media customers from the historical data and play a vital role in deciding what to do next by converting data to information and predicting the outcome of potential actions and events. The diagnostics analytics assist to understand the factors that lead to increased CX, factors that are diminishing brand equity, factors that are leading to positive/negative change, etc. using drill-down, correlations and data discovery. Predictive analytics assist to identify potential risks and opportunities i.e., it helps in determining the brand crisis risk profiles for the digital marketing team and to predict the social media customer emotion. The prescriptive analytics assist on how to get into action to reap appropriate benefits of predictions made to leave a gigantic impact on CX. Though cognitive analytics is still in its infancy, it may be the solution to find real-time answers on the best possible response strategy to a specific crisis by understanding the context, meaning of a sentence, or recognising certain objects in unstructured emotion data. It can reveal certain patterns and deep intelligence that other analytics cannot. For instance, the crisis related to supply chain management can be effectively handled with cognitive analytics i.e., brands need real-time information to strengthen the supply chain and transportation operations to keep up with consumer demands. The visibility, flexibility and integration of global supply chains, as well as market fluctuations and cost pressures, are all major challenges for supply chain executives. Cognitive analytics that are streamlined from data-to-insight and insight-to-action provides supply chain executives with greater visibility, actionable insights, resulting in agile supply chain processes that recognise and learn from the outcomes of previous actions to achieve the organisational goal.

Analytics is characterised by different levels of difficulty, value and intelligence such as descriptive analytics which is related to the question "what has happened?", diagnostic analytics is related to the question "why did it happen?", predictive analytics which is related to the question "what will happen and why will it happen in the future?", prescriptive analytics, which is related to the question "what should I do and why should I do it?" (Lepenioti et al., 2020) and cognitive analytics generates many answers with varied degrees of relevance (Gudivada et al., 2016). Noncognitive analytics like descriptive, diagnostic, predictive, prescriptive uses deterministic algorithms to generate a single answer for each question, whereas cognitive analytics uses probabilistic algorithms (Gudivada et al., 2016). We advocate a technobusiness platform has to provide single answer (e.g., how did the crisis situation was managed?) and/or many answers (e.g., how to recover credibility, repair reputation?) for a single question to improve customer experience following the crisis recovery. We argue that in order to arrive at the optimum answer, noncognitive analytics may have to go through the creation and validation of hypothesis by appropriately structuring the questions and identifying the features/variables that the business intend to measure, manipulate and/or control. The above discussion justifies the inclusion of the component in the proposed platform.

We argue that the advantages offered by analytics-based business platform are: (i) data accumulation from different sources, including internal or external to business, social media, business knowledge base on how the crisis were handled before, etc. (ii) real-time/near-real-time forecasting and monitoring of business following the brand crisis recovery, (iii) identification of crucial points to influence decision on the brand crisis, (iv) identification of issues in the business process in real-time, (v) unlock the true potential of datadriven marketing following the crisis recovery, (vi) response to requests, grievances and queries in real-time in accordance to business rules, (vii) analysis of client or crisis data to produce bespoke products, services, offers, and discounts, among other things.

The proposed AeCX platform is most appropriate for $\mathrm{B} 2 \mathrm{~B}$ and performs emotion analytics/social emotion detection by analysing the emerging emotional patterns from social media or internal data sources, spotting the brand's SWOT (strength, weakness, opportunities, threat) by targeting buyers and prospects, taking care of the critical brand-related issue following a crisis, and produce time-bound actionable insights and probabilistic recommendations that help B2B in optimising decision making to improve $\mathrm{CX}$ resulting in future novelty. By inspecting incoming emotion data from 
social media, AeCX measures an individual's verbal and non-verbal communication to understand their mood or attitude. The aim is to assess an individual's interaction with a brand to identify any weak points that lead to negative reactions following a crisis. Since emotions influence behaviour and happy customers whistle, AeCX can help B2B to tap into their customers' emotions to figure out what makes them tick. The feelings of customers ultimately determine brand loyalty and the likelihood of churning. As a result, using emotion analytics/social emotion detection to track customer sentiment is becoming a more effective way to boost CX. AeCX can be employed either on-premises or in the cloud.

The outcome of the AeCX platform is knowledge creation with time-bound actionable insights and probabilistic recommendations, which help B2B sellers to optimise the decision-making process and might additionally, generate new data for future novelty. Probabilistic approach to recommendations is termed as probabilistic recommendations, which is generative (Truyen et al., 2014). To make more accurate recommendations multi-attributes of the subject of interest (e.g., users, items, crisis severity, crisis type, etc.) must be factored into the probabilistic recommendation model (Wang et al., 2015). Future novelty comes with another level preparedness with new data driven approach to improve CX following the crisis i.e., capabilities to deal with a predetermined scenario are insufficient; capabilities to deal with any type of unusual and large-scale occurrence are needed with optimised decision-making. Time bound actionable insights rethink the crisis situation and push forward to find a new or workable solution. Optimisation of decision making is to find the optimal choice to improve CX with the assessment of criticality of each decision. The above discussion justifies the tangible benefits of the platform.

The inducement matrix (i.e., a matrix to measure CX over a period of time) is used to drive action for each stage. Different recovery plans, implementation plans, strategies and careful communication efforts to be devised for each stage depending on the buyer's positioning and the severity of the crisis. The standard operating procedures (SOP) covering actions for different types of brand crisis, strategy, plans, etc. are beyond the scope of this study. The best way to measure the CX score is to do this over time for each stage and an increase in the score would conclude that the business has improved the CX. Successful closure of the stage is achieved when CX score achieved a satisfactory level and is characterised by a threshold $\%$ of buyers placed in the continue quadrant in the inducement matrix. By using social media and internal data, the technical model performs analytical computation for discovering answers to the key questions. Based on the answers and applying effective response strategies to crisis and brand image restoration strategies such as corrective action and mortification, (Benoit, 1995) action should be made to place as many buyers as possible in the continue quadrant and as few as possible in the other quadrants for each stage.

The model operates in three stages. First, it monitors social media activity and automatically detects all comments, posts, tweets mentioning the brand and such data is ingested into the corpus. This stage is called social monitoring. Second, the data is analysed and classified as "positive", "negative" and "neutral" by performing linguistic analysis and in consultation with corpus. Such data are analysed with a deeper understanding of the sentiments as manifested on social media. This stage is called social analysis. The crisis information i.e., the output of data analysis provides an extensive view of the social media. The result is an analysis of the buyer's attitudes and a better mapping of brand image restoration strategy. If the buyer's attitude toward post crisis is negative, the model progressed to the third stage. This stage is called social recovering, wherein the B2B seller business determines which buyer's need or loop to be closed on most quickly.

\subsection{Theoretical Model}

This study is built upon Social Media Engagement Theory (Di Gangi and Wasko, 2016). The alternative theory (Vargo and Lusch, 2006, 2011) concludes that value co-creation is synonymous with circumstances where the customer and the supplier create the customer experience together. Rawson et al. (2013) recommend defining key journeys for top-down, judgment-driven evaluations and bottom-up, datadriven analysis and then involves the whole organisation to improve customer experience. Such alternative theories are not related to measuring customer experience in the event of post crisis in social media. Social Media Engagement Theory addresses two questions: what determinants shape user interaction in social media and in what way user engagement influences the actions of an individual's social media use and predicts that the user experience, which involves social user interactions, a social media platform's technological features and user engagement. The model did not intend to measure customer experience in the event of post crisis and hence, we extend this model. This study adopted personalisation, perceived risk, and transparency dimensions of social interaction and completeness, evolvability and integration dimensions from technical features. Such dimensions collectively define the construct techno-business features (i.e., TBF) from the context of our study. Central to this model is the SL. The advantage of a crisis is that it lets participants know where things are wrong and allows them to find solutions so that similar crises can be prevented in the future. But these benefits achievable if sufficient steps are taken to learn lessons and apply RTO, RPO wisdom to the brand. So, researchers can implicitly agree that SL matters from the viewpoint of RTO and RPO and its mandate 
to embark on a post-crisis approach purposefully based on the theoretical model.

\subsection{Proposed Conceptual Model}

The study introduced constructs namely recovery time objective (RTO), recovery point objective (RPO), techno-business features (TBF), perceived risk (PR) and social listening (SL) and customer experience (CX) from the perspective of post crisis in social media. The definition/description and reference of each construct are outlined in Table 1.

The study examines CX after recovering from the crisis, by exploring RTO, RPO, TBF, PR and SL from the perspective of the AeCX platform. Fig. 2 represents the

Table 1 Construct definition and its reference

\begin{tabular}{|c|c|c|}
\hline Construct & Definition/description & Reference \\
\hline Recovery time objective (RTO) & $\begin{array}{l}\text { It is the period of time or service level agreement (SLA) during which a business } \\
\text { needs to be restored following a brand crisis to prevent undesirable implications } \\
\text { associated with a break in business continuity. }\end{array}$ & Alhami and Malaiya, 2014 \\
\hline Recovery point objective (RPO) & $\begin{array}{l}\text { It is the period of time or SLA the business loses tolerance in the form of data } \\
\text { i.e., data of search visitors, direct visitors, new visitors, returning visitors and } \\
\text { referral visitors that can be lost before significant harm to the business occurs } \\
\text { following a brand crisis. }\end{array}$ & Alhami and Malaiya, 2014 \\
\hline Social listening (SL) & $\begin{array}{l}\text { It refers to the social media word of mouth (SMWoM) of the brand whose nega- } \\
\text { tive event was centred. The analysis is made of SMWoM conversation around } \\
\text { the brand to make better branding decisions. SL helps to understand why, where } \\
\text { and how these conversations are happening and what B2B participants think. }\end{array}$ & Stewart and Arnold, 2018 \\
\hline Techno-business features (TBF) & $\begin{array}{l}\text { It refers to the features offered by the techno-business model to positively } \\
\text { influence CX. The dimensions of business features are personalisation, social } \\
\text { accessibility and transparency. The dimensions of technical features are com- } \\
\text { pleteness, flexibility, evolvability and integration. Personalisation is the level of } \\
\text { communication with the buyers by paying attention and caring for them in the } \\
\text { event of post brand crisis. Social accessibility is the ability to access different } \\
\text { social media platforms to interact with users post to the brand crisis. Transpar- } \\
\text { ency is the degree of information symmetry among users of the social media } \\
\text { platform and for sellers, such symmetry reduces concerns of opportunistic } \\
\text { behaviour and creates the perception of participation (Di Gangi and Wasko, } \\
\text { 2016). Completeness is defined as the perception of buyers to engage at the } \\
\text { desired specificity level (Di Gangi and Wasko, 2016). Flexibility is defined as } \\
\text { the ability of the seller to make internal changes to the changing buyer's busi- } \\
\text { ness as quickly as possible in the event of post brand crisis i.e., the seller to turn } \\
\text { the risk into opportunity by adjusting to the new paradigm almost immediately. } \\
\text { Evolvability is defined as the degree to which the social media platform evolves } \\
\text { to match the current needs and/or desires of buyers (Di Gangi and Wasko, } \\
\text { 2016). Integration is defined as the degree to which content from different } \\
\text { sources intermingles (Di Gangi and Wasko, 2016). }\end{array}$ & Di Gangi and Wasko, 2016 \\
\hline Perceived risk (PR) & $\begin{array}{l}\text { It is defined as the perception of potential harm that a buyer experiences in the } \\
\text { event of post brand crisis. }\end{array}$ & Stone and Grønhaug, 1993 \\
\hline Customer experience (CX) & $\begin{array}{l}\text { It refers to a customer's holistic perception of their experience with the business, } \\
\text { organisation or brand. }\end{array}$ & Lemke et al.,2011 \\
\hline
\end{tabular}

Fig. 2 Hypothesised conceptual model (Adapted from Di Gangi and Wasko, 2016)

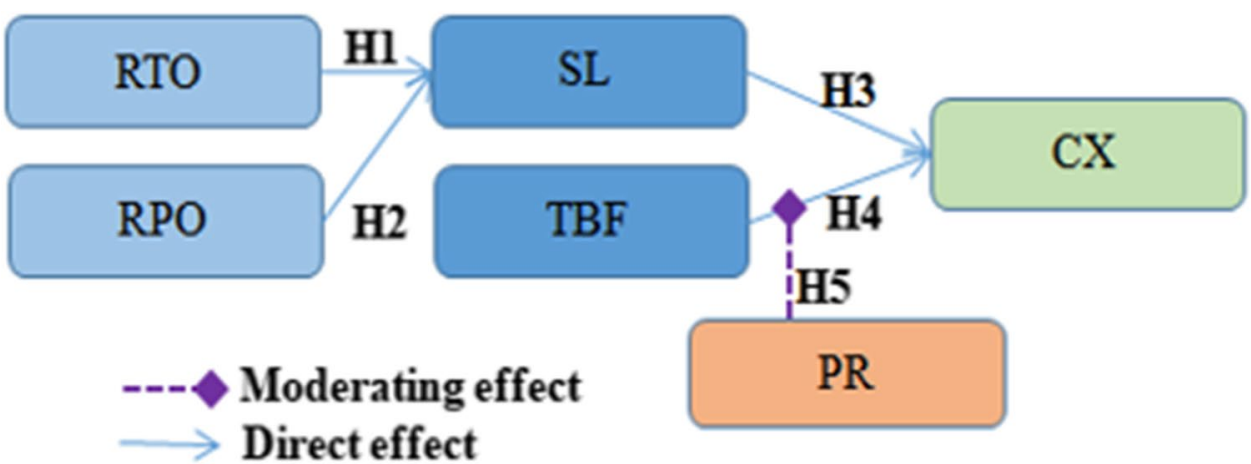


hypothesised conceptual model and is intended to validate the (1) direct effect between (RTO $\rightarrow$ SL) with Hypothesis $\mathrm{H} 1,(\mathrm{RPO} \rightarrow \mathrm{SL})$ with Hypothesis $\mathrm{H} 2,(\mathrm{SL} \rightarrow \mathrm{CX})$ with Hypothesis H3, (TBF $\rightarrow$ CX) with Hypothesis H4, (2) moderating effect between (TBFxPR $\rightarrow$ CX) with Hypothesis H5.

CX metrics such as Net Promoter Score and Customer Overall Score have been created over time to measure different things, but such metrics do not necessarily help when it comes to driving both strategic and operational actions after recovering from a crisis in social media. Hence, it is important to choose the right metric to get the right measure for B2B sellers. We are proposing an inducement matrix based on Brokenbrow (2020) to measure CX over a period of time. The inducement matrix measures $\mathrm{CX}$ on the scale of 1 to 5 (wherein 1: not at all satisfied, 2: not satisfied, 3: disinterestedness, 4: very satisfied, 5: extremely satisfied) over time progression with checkpoints (a lot worse, a little worse, no change, improved a little, improved a lot). The inducement matrix is shown in Fig. 3. It has four quadrants namely Reassess, Continue, Act now and Monitor.

After the crisis, in the progression of time, the satisfaction rating of the buyers is collected and then plotted into an inducement matrix in one of the quadrants. Reassess: Buyers with high satisfaction levels, who have seen some signs of deterioration in the engagement. Continue: buyers with high satisfaction levels who have seen progress or no change in the engagement. Act now: buyers with current low satisfaction levels who have seen no change or signs of deterioration in the engagement. Monitor: buyers with current low satisfaction levels who have seen some signs of progress in the engagement. At any given point in time, the B2B seller intends to see as many buyers as possible in the continue quadrant and as few as possible in the other quadrants. Then the proportion of customers in the continue quadrant concerning other quadrants determines the CX score.

\subsection{Hypotheses Development}

The proposed relationships and hypotheses are discussed below.

\subsubsection{Recovery Time Objective (RTO) $\rightarrow$ Social Listening $(\mathrm{SL})$ and Recovery Point Objective (RPO) $\rightarrow$ Social Listening (SL)}

A shortened RTO can leverage the increased social media coverage and regain positive public sentiment and a shortened RPO can leverage increased social media coverage and regain positive public sentiment. Research suggests that business needs a continuity plan that falls within cost constraints while achieving the target recovery criteria in terms of RTO and RPO (Alhazmi and Malaiya, 2012; Wiboonrat and Kosavisutte, 2008). If the RTO and RPO time are close to zero, the technology driving recovery strategy would be either automatic failover or load balance to reduce the loss (Wiboonrat, 2008). RTO and RPO should be less than or equal to the maximum tolerable period of disruption (Sahebjamnia et al., 2015). Various factors may be considered when architecting a crisis recovery solution and one of the factors may include SLA meeting a tolerable RTO (Chatterjee et al., 2012). SL plays a key role in customer relationship management (Stewart et al., 2017). Following the above studies, we advocate references and recommendations are rife in today's userconnected social media-driven ecosystems and these interactions can ultimately create or destroy the brand in the social community. There is an unspoken expectation that once somebody has commented on the brand on social media, there will be a response. The buyers assume that sellers are listening, so if sellers say nothing, it concludes that ignoring is a choice and nobody likes to be ignored. RTO is the most important parameter in quantifying the brand at an acceptable level in the event of a crisis. Simply put, if the brand reputation is not maintained in social media, the whole house of cards will fall and RTO is essential to the success of business continuity. We advocate that RPO is the most important parameter in quantifying the brand at an acceptable level in the event of a crisis. Simply put, if the brand reputation is not maintained in social media, the whole house of cards will fall, and RPO is essential to the success of business continuity. Therefore, it is hypothesised:
Fig. 3 The inducement matrix showcasing satisfaction rating and the progress of time

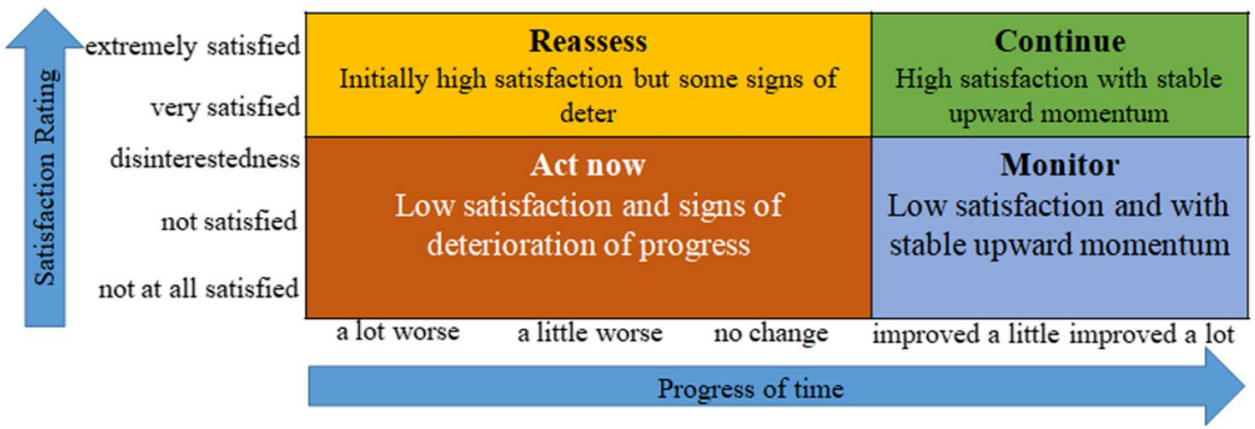


H1: A tolerable recovery time objective (RTO) positively influences social listening (SL).

H2: A tolerable recovery point objective (RPO) positively influences social listening (SL).

\subsubsection{Social Listening (SL) $\rightarrow$ Customer Experience (CX)}

SL is important as it helps to gauge buyer sentiment and plays a pivotal role in customer experience management (CXM). CXMs are the steps an organisation takes to track, control and plan customer experiences. Research suggests that forward-thinking businesses are using SL for actionable insights to measure CX (Bear, 2015). SL platforms are used to get real-time customer insights for products (Bernoff et al., 2011). It is anticipated from SL to provide business value in terms of time to market and increase CX (Morabito, 2014). Analysts are usually able to understand people in their digital context by examining SL data and the importance of communicating with customers in a meaningful way to improve CX (Kelley and Buchanan, 2017). Following the above studies, we advocate that SL helps to understand what problems the buyers have to position and marketing messages to resolve the crisis, what questions buyers ask to identify barriers and confusion in crisis, what solutions the buyers want for the seller to take a new approach in resolving the brand crisis, what other brands are doing wrong, which allows sellers to see the gaps to fill, what buyers think of the brand which allows sellers to see whether the brand need to be changed or to be improved, what other brands are doing right which allows sellers to find a path that might help to please buyers in similar ways. Therefore, it is hypothesised:

H3: Social listening (SL) with to date social sentiment data positively influence customer experience $(C X)$.

\subsubsection{Techno-Business Features (TBF) $\rightarrow$ Customer Experience (CX)}

Business models are fundamentally related to technological innovation and during the crisis, when a techno-business system solves the problem of recognising unsatisfied buyers and address their needs, provide satisfaction and monetize the value results in greater customer satisfaction. Research suggests that if users perceive personalised interactions tailored to their particular needs, CX improves resulting in greater satisfaction and personal relevance (Erat et al., 2006; Kettinger and Lee, 1994). If users are provided flexibility, they are more likely to experience positive experiences and see the techno-business model as significant and fulfilling (Jensen and Aanestad, 2007). Transparency eliminates user concerns about opportunistic behaviour and provides a sense of participation in a trustworthy community (Prahalad and Ramaswamy, 2004). When the social media platform and techno-business model offer detailed information that addresses the needs of the user, it positively affects the user experience (Joinson, 2008; Wixom and Todd, 2005). When businesses have content development resources that suit current user needs, users are more likely to become more active and participatory (Di Gangi and Wasko, 2009). Integration increases the ease with which users can access content from different entry points and limits the creation of barriers that could distract from user engagement feelings (Loebbecke, 2007). Following the above studies, we advocate that making buyers happy is a key part of the techno-business features as they are the assets of sellers and hence is very important to treat them well and retain them in the event of post crisis. Answering the questions in such an event is the most crucial part and with non-effective brand image restoration strategy would raise their frustration, which may increase the churn rate. Therefore, it is hypothesised:

H4: The greater degree of techno-business features (TBF) offered to the buyers facilitates the improvement of customer experience $(C X)$.

\subsubsection{The Moderating Role of Perceived Risk (PR)}

Poor technical and business features in the platform may lead to higher customer churn out. Therefore, such features in the platform have to provide an adequate response for the buyers to get the best value. Research suggests that performance risk is equivalent to the cumulative risk of using a product or service (Mitchell, 1998). When technology failed to produce the desired results, the customer may lose out and discrepancies exist between the assessment of the users and the actual technical results (Im et al., 2008). The analysis of the role of risk in technology-related studies is crucial (Trivedi, 2019). A reduced CR increases CX (Ghotbabadi et al., 2016). CX encompasses every component of a business offering i.e., customer care quality, product and service features, ease of use and reliability (Meyer and Schwager, 2007). Based on the risk-related studies, examining how perceived risk moderates the relationship between the independent and dependent variables becomes important (Im et al., 2008; Tam, 2012; Chen and Huang, 2017). Perceived risk can have a detrimental impact on engagement feelings and eventually deter usage behaviour (Di Gangi and Wasko, 2016) and as a result of the crisis, (Ahern et al., 2007) user concerns about the potential risks of posting on social media have received increased attention, including privacy, opportunistic organisational actions and threats to online identity. Following the above studies, we advocate that higher perceived risk should drive the sellers to become more cautious and to consider the negative 
consequences of the business engagement. Therefore, the moderating effect of perceived risk is observed between TBF and CX leading to the formation of the hypothesis:

H5: The perceived risk (PR) moderates the relationship between techno-business features $(T B F)$ and customer experience $(C X)$.

\section{Methodology}

\subsection{Data Collection}

The data in this study are collected from anonymous Indian B2B businesses that sells/purchase products in the categories of solar products, glass products, drugs and pharmaceuticals, firefighting equipment and water-related products by catering to all sizes of buyers. Such organisations frequently use social media like LinkedIn, Twitter, Facebook, YouTube and Instagram to engage with the buyers and prospects.

The questionnaire was designed for the seller and their buyers. Data were collected through online interviews. Details of the questionnaire are presented in Table 2. Respondents were asked to indicate their preference from the perspective of B2B in exploiting social media for brand building and to improve customer experience after recovering from the brand crisis in social media (i.e., activities performed by B2B in the long-term aftermath of such crisis to restore organisational operations and mitigate the effects of future crises). Twenty five people were chosen for the pilot test of the questionnaire and due to certain difficulties found during the pre-test, the questionnaire's result were altered and hence, adjustments were made accordingly. Based on the pre-test, twenty items that best match the value were used for this study. To shed more light, the respondents were briefed about Maggi noodles crisis and how Nestle adopted the crisis recovery process. The example of brand crisis was in 2015, when Nestle faced a huge crisis when its product Maggi noodles was accused of having high concentrations of lead and monosodium glutamate. Subsequently, social media put the brand in bad light. Nestle recovered from the crisis by creating a frequently asked question (FAQ) page on their website to address all customer questions and convince their customers that the product was safe and good to eat using Twitter and Facebook. Nestle witnessed an improved $\mathrm{CX}$ in addition. Table 2 presents the five-point Likert scale questions (1: Totally disagree, 2: Disagree, 3: Neutral, 4: Agree, 5: Totally agree) and provided to 'digital marketing head' who oversees planning and 'marketing practitioner' who executes marketing strategies and their buyers.

\subsection{Sampling}

The study relied on convenience sampling, as it has been generally accepted and is cost-effective (Ruhl, 2004). All responders were given consent forms and information sheets that explained the study's purpose. The respondents have also been made aware of their right to withdraw participation at any time during the study. To avoid any biases, no gifts or awards were given to the respondents. In total, $58 \mathrm{~B} 2 \mathrm{~B}$ businesses were consented to participate, with four not submitted on time, five not filled out the form completely and three not filled correctly. Therefore, a total of 302 valid responses from 46 valid organisations were considered for further analysis.

\subsection{Research Settings}

Prior to implementation of the AeCX platform, study was conducted. The sellers and buyers were briefed about the platform and the technical/business aspects were thoroughly discussed over video calls. We followed a practical, law-compliant method such as recording and sharing of the conversations, limited participation in the video calls, time break during the calls, offered technical support during discussions, remained flexible to discussion time and maintained professional during the video call. They were also explained in detail on how the data flow into the system in the event of post crisis in social media (SM), how people get to know about what is happening on the platform, how people in $\mathrm{B} 2 \mathrm{~B}$ business come together to discuss crisis affecting the business, how people in B2B business come together to discuss brand crisis affecting the SM community, what should be the perception of potential buyers of negative WoM posted in SM, how people regard beliefs to SM post, how buyer and seller respect trust and relationship to post crisis in SM.

\subsection{Common Method Bias}

This study is also vulnerable to common method bias (CMB), which arises from the fact that it is a self-reported survey, with respondents being asked to respond to a standard scale of constructs and respondents being asked questions that affect both independent and dependent variables at the same time (Podsakoff et al., 2003). As a result, we used Harman's single-factor test, which is the most frequent method for assessing CMB (Malhotra et al., 2006). As per Harman's single-factor test, the cumulative variance value of $28.096 \%$ is well below the $50 \%$ threshold, indicating the absence of the CMB. 


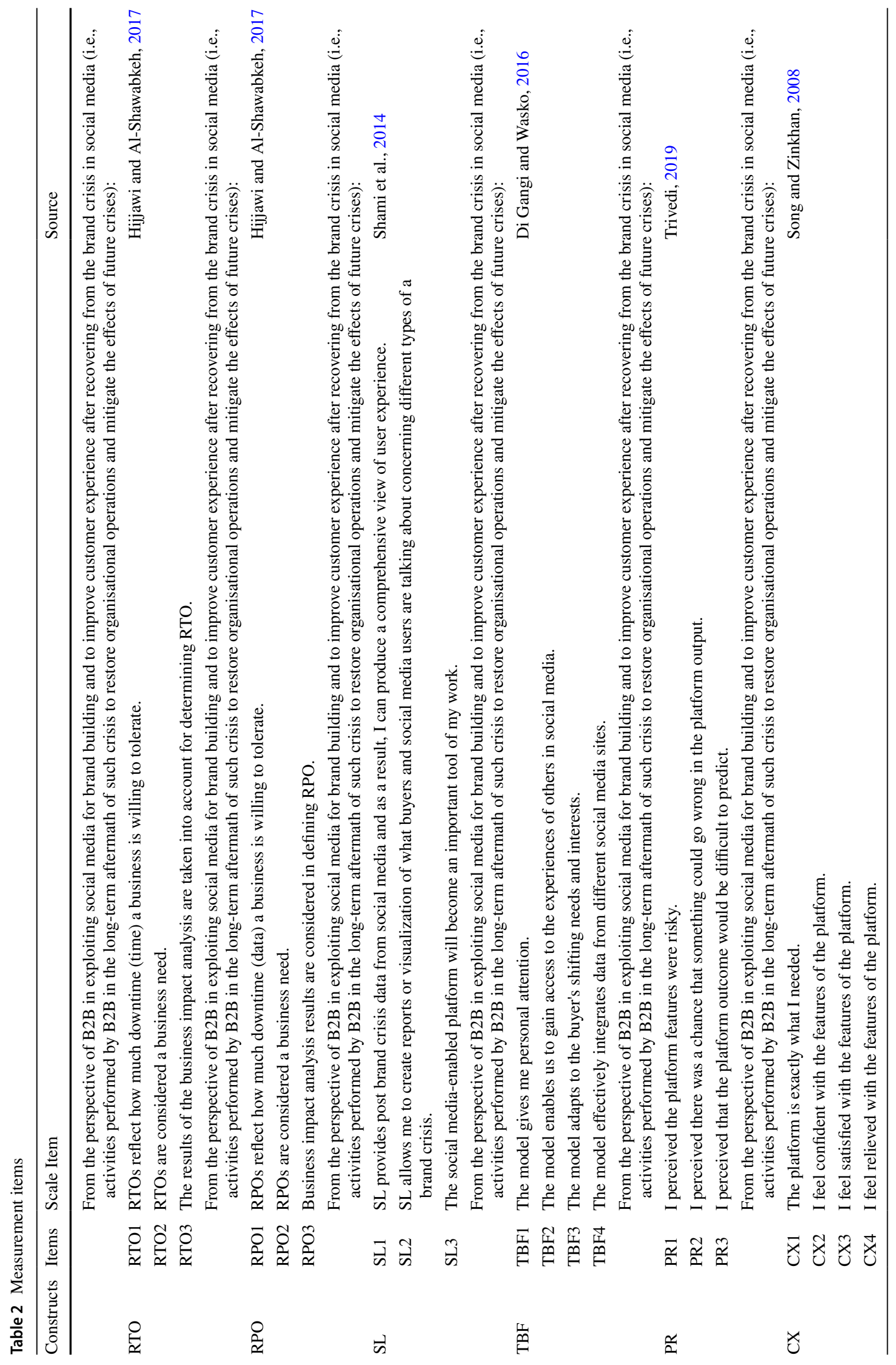


Table 3 B2B organisation and respondent profile

\begin{tabular}{lllll}
\hline Characteristics & $\begin{array}{l}\text { \# of } \\
\text { organisa- } \\
\text { tions }\end{array}$ & $\begin{array}{l}\text { Organisa- } \\
\text { tion propor- } \\
\text { tion }\end{array}$ & $\begin{array}{l}\text { \# of respond- } \\
\text { ent }\end{array}$ & $\begin{array}{l}\text { Respond- } \\
\text { ent pro- } \\
\text { portion }\end{array}$ \\
\hline Less than 50 & 10 & $22 \%$ & 36 & $12 \%$ \\
$50-99$ & 4 & $9 \%$ & 69 & $23 \%$ \\
$100-249$ & 12 & $25 \%$ & 54 & $18 \%$ \\
$250-499$ & 13 & $29 \%$ & 85 & $28 \%$ \\
More than & 7 & $15 \%$ & 58 & $19 \%$ \\
500 & & & & \\
& 44 & $96 \%$ & 285 & $94 \%$ \\
Until 5 & 4 & $4 \%$ & 17 & $6 \%$ \\
More than 5 & 2 & $100 \%$ & 302 & $100 \%$ \\
Total & 46 & Existence in Years & \\
\hline
\end{tabular}

\section{Data analysis and Results}

The proposed research model was tested using Exploratory Factor Analysis (EFA), Confirmatory Factor Analysis (CFA) and Structural Equation Modelling (SEM). Table 3 shows the respondents and their organisation profiles, with the majority of respondents' organisations having been in operation for less than 5 years. In a similar notation, other characteristics of $\mathrm{B} 2 \mathrm{~B}$ organisations and respondents considered from them are presented in Table 3.

\subsection{Measurement Model}

The data analysis and results consists of a two-step approach that included a measurement model and a structural model (Anderson and Gerbing, 1988) and the purpose is to determine construct validity and reliability before analysing the suggested model's structural relationship. As per Fornell and Larcker(1981) and Hair et al. (2006), the convergent reliability of all factors evaluated in the measurement model is reached with factor loadings, average variance extracted value (AVE) values greater than 0.5 and Cronbach's alpha (CA), composite reliability (CR) values greater than 0.7 . Table 4 shows the CA, CR, and AVE values for the constructs employed in this study are all greater than 0.7 , while the AVE value is greater than 0.5. As a result, it may be argued that the measurement model's factors are reasonably dependable, and the convergent validity conditions have been met.

To avoid multicollinearity, all constructs' correlations should be less than 0.85 (Kline, 2015). Table 5 shows that all diagonal elements in the corresponding rows and columns were higher than off-diagonal elements, demonstrating that all diagonal elements in the corresponding rows and columns were higher than off-diagonal elements and that
Table 4 Convergent validity and internal reliability

\begin{tabular}{|c|c|c|c|c|c|}
\hline Constructs & Items & FL & CA & CR & AVE \\
\hline \multirow[t]{3}{*}{ RTO } & RTO1 & 0.694 & \multirow[t]{3}{*}{0.750} & \multirow[t]{3}{*}{0.779} & \multirow[t]{3}{*}{0.543} \\
\hline & RTO2 & 0.661 & & & \\
\hline & RTO3 & 0.637 & & & \\
\hline \multirow[t]{3}{*}{ RPO } & RPO1 & 0.902 & \multirow[t]{3}{*}{0.880} & \multirow[t]{3}{*}{0.881} & \multirow[t]{3}{*}{0.712} \\
\hline & RPO2 & 0.903 & & & \\
\hline & RPO3 & 0.878 & & & \\
\hline \multirow[t]{3}{*}{ SL } & SL1 & 0.743 & \multirow[t]{3}{*}{0.845} & \multirow[t]{3}{*}{0.845} & \multirow[t]{3}{*}{0.646} \\
\hline & SL2 & 0.735 & & & \\
\hline & SL3 & 0.678 & & & \\
\hline \multirow[t]{4}{*}{ TBF } & TBF1 & 0.849 & \multirow[t]{4}{*}{0.893} & \multirow[t]{4}{*}{0.889} & \multirow[t]{4}{*}{0.671} \\
\hline & TBF2 & 0.806 & & & \\
\hline & TBF3 & 0.834 & & & \\
\hline & TBF4 & 0.868 & & & \\
\hline \multirow[t]{3}{*}{ PR } & PR1 & 0.879 & \multirow[t]{3}{*}{0.839} & \multirow[t]{3}{*}{0.840} & \multirow[t]{3}{*}{0.638} \\
\hline & PR2 & 0.839 & & & \\
\hline & PR3 & 0.873 & & & \\
\hline \multirow[t]{4}{*}{$\mathrm{CX}$} & CX1 & 0.709 & \multirow[t]{4}{*}{0.838} & \multirow[t]{4}{*}{0.837} & \multirow[t]{4}{*}{0.563} \\
\hline & $\mathrm{CX} 2$ & 0.728 & & & \\
\hline & $\mathrm{CX} 3$ & 0.732 & & & \\
\hline & CX4 & 0.740 & & & \\
\hline
\end{tabular}

all estimates of inter-correlations were below 0.738 , demonstrating discriminant validity.

\subsection{Structural Model}

A p-value of less than 0.05 denotes statistical significance and hence the hypothesis is accepted (Blanchard et al., 2011). Table 6 captures hypotheses testing result and illustrate the relations between RTO and SL $(p<0.05)$, RPO and SL $(p>0.05)$, SL and SX $(p<0.05)$, and TBF and CX $(p<0.05)$. Thus, $\mathrm{H} 1, \mathrm{H} 3, \mathrm{H} 4$ were supported and $\mathrm{H} 2$ was not supported.

Table 7 captures the summary of moderator (i.e., PR) effect and illustrates the indirect relations between TBF and PR $(\mathrm{p}<0.05)$, PR and CX $(\mathrm{p}<0.05)$. Thus, H5 was supported.

AMOS version 21.0.0 was used to examine the path coefficient $(\beta)$ and $R^{2}$ value. The result of the SEM path and $R^{2}$ is shown in Fig. 4. An $R^{2}$ value of 0.56 of SL and 0.59 of CX is considered to be a good fit.

\section{Discussion}

Overall, the results provide evidence that social media channels and the techno-business features of the AeCX platform have become customer experience platforms in the event of post crisis. Therefore, this research is the first influence 
Table 5 Correlation matrix of constructs

Table 6 Hypotheses testing results

Table 7 Moderator effect of Hypothesis H5

\begin{tabular}{lllllll}
\hline Constructs & CX & TBF & PR & SL & RTO & RPO \\
\hline CX & $\mathbf{0 . 7 5 0}$ & & & & & \\
TBF & 0.390 & $\mathbf{0 . 8 1 9}$ & & & & \\
PR & -0.080 & 0.150 & $\mathbf{0 . 7 9 8}$ & & & \\
SL & 0.738 & 0.447 & 0.053 & $\mathbf{0 . 8 0 3}$ & & \\
RTO & 0.708 & 0.415 & 0.056 & 0.723 & $\mathbf{0 . 7 3 7}$ & \\
RPO & 0.042 & 0.046 & -0.044 & 0.127 & 0.118 & $\mathbf{0 . 8 4 4}$ \\
\hline
\end{tabular}

\begin{tabular}{llllllll}
\hline Hypotheses & Relation & Std. Beta & Std. Error & t-value & p-value & HTR & Significance \\
\hline H1 & RTO $\rightarrow$ SL & 0.75 & 0.074 & 8.937 & $* * *$ & Accept & Highly significant \\
H2 & RPO $\rightarrow$ SL & 0.05 & 0.044 & 0.904 & 0.366 & Reject & Not significant \\
H3 & SL $\rightarrow$ CX & 0.75 & 0.075 & 10.306 & $*$ & Accept & Significant \\
H4 & TBF $\rightarrow$ CX & 0.12 & 0.048 & 2.395 & $*$ & Accept & Significant \\
\hline
\end{tabular}

[HTR represents the hypothesis testing result. *** denotes $p<0.001$, ** denotes $p<0.01$, $*$ denotes $p<$ $0.05]$

\begin{tabular}{lllllll}
\hline Relation & Std. Beta & Std. Error & t-value & p-value & HTR & Significance \\
\hline $\mathrm{TBF} \rightarrow \mathrm{PR}$ & 0.15 & 0.078 & 2.326 & $*$ & accept & Significant \\
$\mathrm{PR} \rightarrow \mathrm{CX}$ & -0.14 & 0.042 & -2.550 & $*$ & accept & Significant \\
\hline
\end{tabular}

HTR represents the hypothesis testing result. *** denotes $p<0.001$, ** denotes $p<0.01$, * denotes $p<0.05$

Fig. $4 \mathrm{R}^{2}$ and $\beta$ result of $\mathrm{AeCX}$ platform

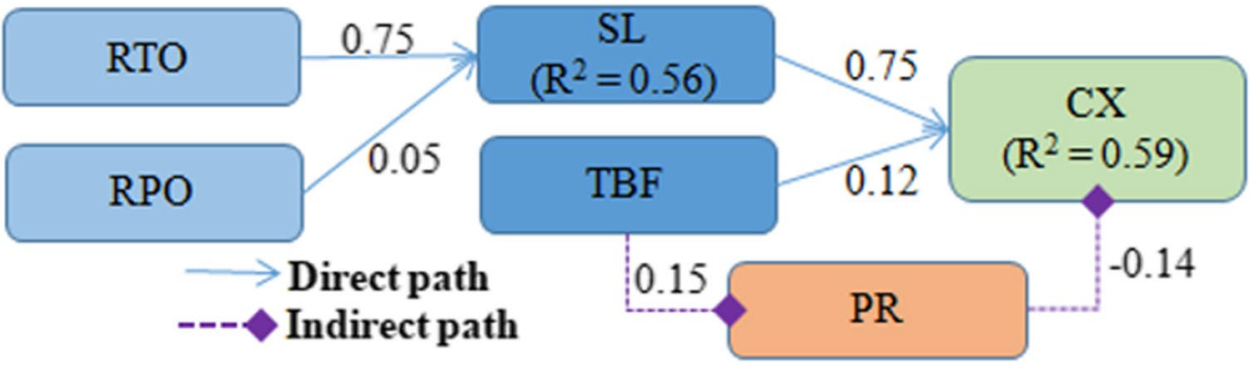

Table 8 Model fit indices

\begin{tabular}{llll}
\hline Test & Value & Ref value & Reference \\
\hline CMIN/DF & 2.662 & {$[1-3]$} & Hooper et al., 2008 \\
RMSEA & 0.074 & $0.05-0.10$ & MacCallum et al., 1996 \\
GFI & 0.850 & 0.90 & Tanaka and Huba, 1989 \\
IFI & 0.888 & 0.90 & Bollen, 1989 \\
TLI & 0.874 & 0.90 & Tucker and Lewis, 1973 \\
NFI & 0.832 & 0.90 & Bentler and Bonett, 1980 \\
\hline
\end{tabular}

tactics study that can be managerially relevant to all B2B seller businesses hoping to fulfil the customer experience in the time of crisis. The study revealed that post to the crisis, "people's watching" to social media needs extreme attention and timely resolution with techno-business features of the
AeCX platform focusing on CX play out exceptional experiences among the buyers again and again.

Tables 6 and 7 depict the hypothesis test summary of the study and Table 8 depicts the model fit indices. From the results it is recommended to adopt the AeCX Platform to $\mathrm{B} 2 \mathrm{~B}$ digital marketing practices to improve $\mathrm{CX}$ post to the crisis.

The study finds support for all hypotheses H1, H3, H4 and $\mathrm{H} 5$ except H2. Significant positive relationships are observed between (i) RTO and SL, (ii) SL and CX, (iii) TBF and CX and (iv) TBF and PR. Meanwhile, PR emerged as a significant negative predictor towards CX. Post crisis, RTO plays a significant factor in business continuity between buyer and seller. A lower RTO results in better SL as it can spot a trend and B2B can address right away, which creates goodwill with the customers and boost engagement. 
RPO does not play a significant role as most of the B2B perceived it to be correlated with the visitors or prospects and the buyers are not impacted for business analysis and business continuity. However, B2B voiced RPO can be an important consideration for disaster business recovery planning. SL plays a significant role in increasing $C X$ as it helps to gauge buyer sentiment, manage brand reputation, build brand loyalty, etc. TBF of the AeCX platform plays a crucial role as it helps to analyse what problems the buyers have, what questions buyers ask, what solution the buyers want, what other brands are doing right, what buyers think of a post to the crisis. PR and CX are inversely related i.e., with the increase of PR, CX tends to decrease.

The findings indicate four important outcomes. First, from the crisis viewpoint is consistent with $(\mathrm{Xu}$ and $\mathrm{Li}$, 2013) with the distinguishing characteristics of brand crises in social media, which results in severe consequences in social media, threats to the fundamental value of the business, limitations in RTO and unexpectedness of the crisis event. (Utz et al., 2013) communication of the brand crisis through social media has a stronger effect than newspapers on business reputation. (Benoit, 1995) two brand image restoration strategies are suitable out of five and are corrective action: outline improvements to prevent a recurrence and mortification: acknowledging the incident, taking responsibility, apologizing, and asking for forgiveness. (Grundy and Moxon, 2013) in certain situations, the presence of the chief executive officer (CEO) during a crisis contributes to the impression that marketing leadership is responsible for the crisis and shows due regard for it. (Hemus, 2010) if a crisis hits at the root of brand values in social media, it can do most harm. In news media, social media content shared during crises is increasingly being used to describe the response of the public (Smith et al., 2018).

Second, from the CX viewpoint is consistent with (Lemke et al., 2011) the credibility of the social media and quality of brand restoration communication in such social media has a significant effect. (Zolkiewski et al., 2017) existing measures of customer experience such as NPS, COS, and CES are problematic and a strategic approach is required to capture and manage CX. (Zhang et al., 2016) customer experience has a strong effect on the brand relationship. Usage of digital and emerging technology enhances customer experience (Parise et al., 2016; Blázquez, 2014). Perceived risk is significant with a strong negative relationship with customer experience (Johnson et al., 2006; Martin et al., 2015).

Third, from the perceived risk viewpoint is consistent with PR is associated with different technology platforms and plays a major role in understanding online customer behaviour (Lopez-Nicolas and Molina-Castillo, 2008). A higher level of PR decreases the utilitarian benefit effect (Chiu et al., 2014). PR can be perceived as cognitive and affective intermediate states that fluctuate with online ambient indications (Chang and Chen, 2008).

Fourth, if the crisis results in a major issue and despite all attempt customers are walking away from it, rebranding (Muzellec et al., 2003; Daly and Moloney, 2005) should be attempted by B2B to resolve crises. Cloud-based analytical platforms, data and analytics play an important role from business stability in setting the groundwork for new processes and predicting the next actions. As a result, it is important for B2B to get short, medium and long-term data-driven plans in place to help in time-bound decisionmaking. The three key sequential data-driven pathways such as resilience, realignment and recovery should be adopted to maximise the chances of emerging with prosperity from the serious crisis. In the resilience phase, B2B should finetune the platform and leverage the cloud. In the realignment phase, B2B should optimise and modernise data and platform infrastructure. In the recovery phase, B2B invests in tools that focus on speed, performance, scale and future growth.

\subsection{Theoretical Contributions}

The current study is valuable for research and industry in the field of B2B digital marketing and analytics. It extensively explores $C X$ after recovering from the crisis in social media. Previous studies focused on online customer experience (OCE) within B2B websites and revels that the credibility of the website and the accuracy of the website information have a significant effect on the OCE (McLean, 2017). Quality of customer experience is measured in terms of its valuein-use performance, and it mediates between the quality of the experience and outcomes of relationships (Lemke et al., 2011). The CX has a positive effect on four brand equity dimensions including, brand awareness, brand associations, perceived quality and brand loyalty (Biedenbach and Marell, 2010). None of the studies discussed the CX post crisis, neither in social media or traditional media like newspaper, television, or radio.

This study also analysed each construct in the backdrop of the empirical result and highlights contribution to the body of knowledge.

RTO and RPO: The buyer calculates business impact analysis and business continuity based on RTO and RPO i.e., both play the role of determinants for the risk assessment process that determines the list of risks and potential losses. RTO and RPO provide pragmatic recommendations for improvement and help to develop the crisis recovery and communication strategy. A successful RTO and RPO analysis provide the opportunity to prioritize certain functions and assign sufficient resources to make sure the business is minimally impacted. Senior management place limits on 
RTO and RPO based on the crisis severity and resulting cost considerations to minimize damage.

SL: SL is essential to build a solid reputation in social media post to the crisis. Buyers want to feel heard on social media, so when the seller responds to post crisis questions or queries other buyers and potential customers join the conversation, it gives a brand responsiveness impression to buyers and prospects on social media. Such thoughtfully craft responses provide real value, elicit brand loyalty, and increase customer retention rates. SL helps to discover the contents for buyers, potential customers by following them, and liking their posts, hashtags, and photos and then create relevant content that matches their taste, which ultimately draws their attention to close the crisis.

CX: Customer-centric mindset is critical for B2B sellers, specifically in the event of post crisis and executives must develop a strategy to maximize it with a striking result. Realtime responsiveness and easy-to-use social media apps set a high standard for speed and business efficiency to improve customer experience. CX is becoming a way of standing out from its low-cost competitors in the event of post crisis. $\mathrm{B} 2 \mathrm{~B}$ is not a single customer-driven engagement, so it is not always possible to ensure a consistent $\mathrm{CX}$ for everyone in the event of post crisis. Customer journeys are simply more complex in the event of post crisis, very often limited products and delivery services bundled together, and delivery is expected to be free of cost for buyers.

PR: Earning CX requires exceptional effort, as a relatively steady stream of social media post- crisis makes buyers more cynical in B2B business involvement. Without superior techno-business features of the platform buyers immediately sense the loss of value in the business engagement, which leads to the perceived risk of declining CX. Post to the crisis, every interaction with the buyer is an opportunity to make interaction to better understand their needs and wants, including monitoring and analysing their sentiments. Half of the battle is monitoring sentiments and the other half of the battle is to leverage the analysis to better serve them, regardless of what and how they choose to proceed with the business engagement.

AeCX Platform: The platform can be plug-and-play i.e., in the event of post crisis, the prospects can easily engage and disengage with the platform which the buyers typically do not. The additional need of the platform is secure, high cohesive, and loosely coupled.

\subsection{Implications for Practice}

Our findings have important managerial implications and would be particularly valuable to B2B marketers. The current research provides insights for B2B marketers and executives who may be interested in taking advantage of the AeCX platform and explains why attention should be paid to SL and TBF to judge the improved CX. However, the greatest promise will be realised by building a CX funnel illustrating the positive impact on the buyer in social media. Fig. 5 represents the CX funnel, wherein each R represents the 5 stages of the business model.

With the passage of time and dealing with buyers at different stages, the combination of the increased CX score, captured through inducement matrix and the increased positive WoM in social media of the brands indicates increase CX. The CX funnel illustrates the path buyers take. Understanding the funnel helps the sellers to find the holes in the funnel where buyers can drop out and never convert. Each stage of the funnel requires a different approach and might need tweaks depending on the severity of the crisis. Our proposal on the urgency and types of questions to be asked during such conversations is narrated in Table 9, which is grounded on (Brokenbrow, 2020).

Fig. 5 CX funnel

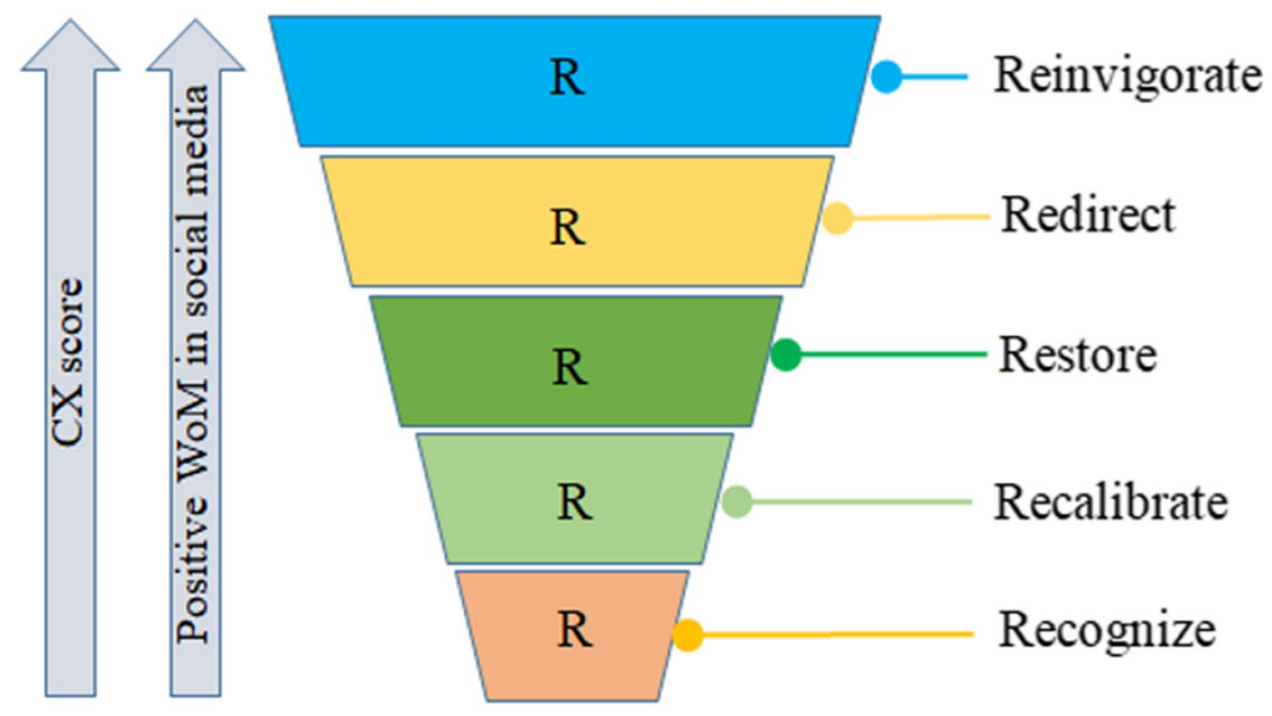


Table 9 Urgency and question types of each quadrant

\begin{tabular}{lll}
\hline Quadrant & Urgency of closing the loop & Conversation \\
\hline Act Now & Urgent and critical & Why are not buyers satisfied? \\
Reassess & Urgent and important & What negative changes are buyers noticing? \\
Monitor & Urgent but no important & What positive changes are buyers watching? \\
Continue & Urgent but no important & What are buyers highly satisfied? \\
\hline
\end{tabular}

Table 10 Closing criteria for each stage of the AeCX platform

\begin{tabular}{lll}
\hline Stage & BIRS & PBCCS \\
\hline Recognise & Mortification & Full apology \\
Recalibrate & Corrective Action & Ingratiation \\
Restore & Corrective Action & Justification \\
Redirect & Corrective Action & Corrective action \\
Reinvigorate & Corrective Action & Ingratiation \\
\hline
\end{tabular}

BIRS symbolises brand image restoration strategy, and PBCCS symbolizes post brand crisis communication strategy.

Strategically, it is equally important to close the loop with the buyers for each stage in the business model. Our proposal in closing criteria for each stage is narrated in Table 10. In the table, brand image restoration strategy is based on (Benoit, 1995) and post brand crisis communication strategy is based on (Coombs, 1998).

Customers who are highly committed to the brand are more likely to argue against the negative information than consumers who are lowlily committed to the brand (Ahluwalia et al., 2000). Therefore, the buyer's commitment to the crisis brand mitigates the brand's negative effects. Brand crises arise more often in the uncertain markets because of the growing complexity of products, increasingly demanding customers and more prevalent social media (Dawar and Pillutla, 2000), and post crisis, the seller business needs to restore trust in the eyes of buyers, with shortening RTO and RPO to improve CX.

To successfully execute a platform strategy, the seller must become a magnet: attract a meaningful number of right participants, both right producers and right consumers of the business, act as a matchmaker: enabling producers to match the right producers with a search engine matchmaking mechanism at its most basic level and toolkit offer: the toolkit is to enable the producer for easy plug-and-play of prospects and providing data orchestration is so critical to seller pursuing platform strategies.

\subsection{Limitations and Future Research}

Like any other research, this study also has some limitations. First, a small dataset was considered for this study and the primary data was collected from B2B sellers and their buyers operated out of India. B2B digital market is gradually maturing across the world, whereas in India it is still at the nascent stage. While the theoretical framework is expected to be generalisable, the outcomes would have been better if the data collections were performed post to the implementation of the proposed model in India or at the matured B2B businesses operating in developed countries. Second, the combination of customer retention and customer loyalty measures how satisfied is buyers with the experience of the post crisis and how likely they would share the experience with others. Due to data limitation, the study could not discover the findings on such dimensions. Third, the research could assess the hyper-personalised customer experience tailored to their need and want of the buyers in the event of post crisis presents a dilemma for social media marketers, therefore actionable ideas to create compelling content can lead to a winning customer experience.

The future research agenda address better selection of sample data, improvement of customer loyalty and customer retention, and hyper-personalised customer experience. First, B2B firms can conduct the survey in developed countries' post to the implementation of the system to perceive the true value of technical and business features of the AeCX platform. The result might witness (1) support for hypothesis H2, i.e., the relationship between recovery point objective and social listening, and (2) better support for hypothesis $\mathrm{H} 4$ i.e., the relationship between techno-business features and customer experience concerning path coefficients.

Second, customer loyalty helps a business to boost its brand identity and eventually helps a brand to attract more customers and increase $\mathrm{CX}$ as well as brand loyalty. The "relationship lock-in" is greater loyalty to the B2B markets. B2B businesses that focus on customer retention and loyalty building will survive and thrive in the event of post crisis in social media, hence the authors advocate for the establishment of customer loyalty building theory and customer retention theory. The theory may be based on the questions: how satisfied the buyers with the quality of the products are, how satisfied are the buyers with the reliability of products, how satisfied are the buyers with the value for money of products, how satisfied are the buyers with the sales service, how satisfied are the buyers with the speed of delivery and how satisfied are the buyers with the reliability of delivery.

Third, to beat the competition, B2B sellers can be the early adopter of hyper-personalisation strategy in improving customer experience by reaping business benefits. The 
artificial intelligence and analytic powered technique can be used more effectively in a hyper-personalisation strategy to shift the relationship from selling to relationship building in the event of post crisis.

\section{Conclusion}

In this study, a techno-business platform (AeCX) is proposed to measure customer experience $(\mathrm{CX})$ after recovering from the crisis, by exploring recovery time objective (RTO), recovery point objective (RPO), techno-business features (TBF), perceived risk (PR) and social listening (SL). The theoretical model is founded on Social Media Engagement Theory. The constructs RTO, RPO, SL, TBF, PR and CX were explained from the perspective of post crisis in social media. This study articulated a 5-stage business model for post crisis recovery and the techno-business model. The inducement matrix is proposed to measure $\mathrm{CX}$ over a period of time and the SEM technique was applied to validate the goodness of model fit. The dawn of social media has opened the world's eyes to the importance of CX in the event of post crisis for $\mathrm{B} 2 \mathrm{~B}$. The experience behind a brand is the primary source of differentiation and the basis for brand positioning, and nothing drives WoM advertising in social media like great CX. As outlined in the paper, the cornerstone in winning back customer confidence is to adopt appropriate brand image restoration and communication strategy by maintaining a steady $\mathrm{CX}$ in each stage of post brand crisis recovery strategy. Apart from improving CX, B2B must pay importance to long-term economic impact, and the growth solution. Precisely, the research contributes to the B2B marketing literature by presenting the techno-business model to improve customer experience after recovering from the crisis, catering to diversified industries.

\section{References}

Acheampong, F. A., Wenyu, C., \& Nunoo-Mensah, H. (2020). Textbased emotion detection: Advances, challenges, and opportunities. Engineering Reports, 2(7), e12189.

Ahern, S., Eckles, D., Good, N. S., King, S., Naaman, M., \& Nair, R. (2007). Over-exposed? Privacy patterns and considerations in online and mobile photo sharing. In Proceedings of the SIGCHI Conference on Human Factors in Computing Systems., 357-366.

Ahluwalia, R., Burnkrant, R. E., \& Unnava, H. R. (2000). Consumer response to negative publicity: The moderating role of commitment. Journal of Marketing Research, 37(2), 203-214.

Alhami, O. H., \& Malaiya, Y. K. (2014). Are the classical disaster recovery tiers still applicable today? In 2014 IEEE International Symposium on Software Reliability Engineering Workshops.144-145.

Alhazmi, O. H., \& Malaiya, Y. K. (2012). Assessing disaster recovery alternatives: On-site, colocation or cloud. In 2012 IEEE 23rd International Symposium on Software Reliability Engineering Workshops. 19-20.

Anderson, J. C., \& Gerbing, D. W. (1988). Structural equation modeling in practice: A review and recommended two-step approach. Psychological Bulletin, 103(3), 411-423.

Baghdadi, Y. (2004). A business model for B2B integration through Web services. Proceedings IEEE International Conference on e-Commerce Technology, CEC, 2004, 187-194.

Baliga, A. J., Chawla, V., Ganesh, L. S., \& Sivakumaran, B. (2021). Service Failure and Recovery in B2B Markets-A Morphological Analysis. Journal of Business Research, 131, 763-781.

Bao, S., Xu, S., Zhang, L., Yan, R., Su, Z., Han, D., \& Yu, Y. (2009). Joint emotion-topic modeling for social affective text mining. In 2009 Ninth IEEE International Conference on Data Mining, 699-704. IEEE.

Bauer, D., Froese, F., Garcés-Erice, L., Giblin, C., Labbi, A., Nagy, Z. A., Pardon, N., Rooney, S., Urbanetz, P., Vetsch,P., \& Wespi, A. (2021). Building and Operating a Large-Scale Enterprise Data Analytics Platform. Big Data Research, 23, 100181.

Bear, M. (2015). Survival of the fittest: Using social media to thrive in the 21st century. Journal of Brand Strategy, 4(2), 106-113.

Behera, R. K., Bala, P. K., \& Ray, A. (2021). Cognitive Chatbot for Personalised Contextual Customer Service: Behind the Scene and beyond the Hype. Information Systems Frontiers, 1-21.

Benoit, W. L. (1995). Accounts, excuses, and apologies: A theory of image restoration strategies. State University of New York Press.

Bentler, P. M., \& Bonett, D. G. (1980). Significance tests and goodness of fit in the analysis of covariance structures. Psychological Bulletin, 88(3), 588.

Bernoff, J., Cooperstein, D., Lussant, M., \& Munchbach, C. (2011). Competitive Strategy in the Age of the Customer. CMO \& Marketing Leadership Professionals, Forrester. Retrieved from http://boxonline.s3.amazonaws.com/SM/Forrester_Age_of_ Customer_Report.pdf. Accessed on 12th July 2020.

Beverland, M., \& Ewing, M. (2005). Slowing the adoption and diffusion process to enhance brand repositioning: The consumer driven repositioning of Dunlop Volley. Business Horizons, 48(5), 385-391.

Beverland, M., Lindgreen, A., Napoli, J., Kotler, P., \& Pfoertsch, W. (2007). Being known or being one of many: the need for brand management for business-to-business (B2B) companies. Journal of Business \& Industrial Marketing, 22(6), 357-362.

Biedenbach, G., \& Marell, A. (2010). The impact of customer experience on brand equity in a business-to-business services setting. Journal of Brand Management, 17(6), 446-458.

Birch, J. (1994). New factors in crisis planning and response. Public Relations Quarterly, 39(1), 31.

Blanchard, P., Baujat, B., Holostenco, V., Bourredjem, A., Baey, C., Bourhis, J., \& Pignon, J. P. (2011). Meta-analysis of chemotherapy in head and neck cancer (MACH-NC): a comprehensive analysis by tumour site. Radiotherapy and Oncology, 100(1), $33-40$.

Blázquez, M. (2014). Fashion shopping in multichannel retail: The role of technology in enhancing the customer experience. International Journal of Electronic Commerce, 18(4), 97-116.

Bollen, K. A. (1989). A new incremental fit index for general structural equation models. Sociological Methods \& Research, 17, 303-316.

Bosco, C., Patti, V., \& Bolioli, A. (2013). Developing corpora for sentiment analysis: The case of irony and senti-tut. IEEE Intelligent Systems, 28(2), 55-63.

Brokenbrow M. (2020). The Momentum Matrix - A Customer Experience Framework [Blog post]. Retrieved from https://www.b2bin ternational.com/publications/the-momentum-matrix-a-customerexperience-framework. Accessed on 12th August 2020. 
Cambria, E., \& White, B. (2014). Jumping NLP curves: a review of natural language processing research. IEEE Computational Intelligence Magazine, 9(2), 48-57.

Caruso, F., \& Umar, A. (2004). Architectures to survive technological and business turbulences. Information Systems Frontiers, $6(1), 9-21$.

Chan, T. Y., Li, J., \& Pierce, L. (2014). Learning from peers: Knowledge transfer and sales force productivity growth. Marketing Science, 33(4), 463-484.

Chang, H. H., \& Chen, S. W. (2008). The impact of online store environment cues on purchase intention. Online information Review, 32(6), 818-841.

Charlebois, S., \& Elliott, G. (2009). Mining for Mindsets: The Conceptual Anatomy of a Successful Crisis Communication Strategy in Mining. Journal of Marketing Communications, 15(1), 55-71.

Chatterjee, P., Jayaraman, R., Ranganathan, L., \& Maliakal, J. (2012). U.S. Patent No. 8,332,354. Washington, DC: U.S. Patent and Trademark Office.

Chen, Y. S., \& Huang, S. Y. (2017). The effect of task-technology fit on purchase intention: The moderating role of perceived risks. Journal of Risk Research, 20(11), 1418-1438.

Chiu, C. M., Wang, E. T., Fang, Y. H., \& Huang, H. Y. (2014). Understanding customers' repeat purchase intentions in B2C e-commerce: the roles of utilitarian value, hedonic value and perceived risk. Information Systems Journal, 24(1), 85-114.

Claro, D. P., \& Kamakura, W. A. (2017). Identifying sales performance gaps with internal benchmarking. Journal of Retailing, 93(4), 401-419.

Comfort, L. K. (2007). Crisis management in hindsight: Cognition, communication, coordination, and control. Public Administration Review, 67, 189-197.

Coombs, W. T. (1998). An analytic framework for crisis situations: Better responses from a better understanding of the situation. Journal of Public Relations Research, 10(3), 177-191.

Coombs, W. T. (2007). Protecting organization reputations during a crisis: The development and application of situational crisis communication theory. Corporate Reputation Review, 10(3), 163-176.

Coombs, W. T., \& Holladay, S. J. (2012). Amazon.com's Orwellian Nightmare: Exploring Apology in an Online Environment. Journal of Communication Management, 16(3), 280-295.

Cortez, R. M., \& Johnston, W. J. (2020). The Coronavirus crisis in B2B settings: Crisis uniqueness and managerial implications based on social exchange theory. Industrial Marketing Management, $88,125-135$

Daly, A., \& Moloney, D. (2005). Managing corporate rebranding. Irish Marketing Review, 17(1/2), 30-36.

Dawar, N., \& Lei, J. (2009). Brand crises: The roles of brand familiarity and crisis relevance in determining the impact on brand evaluations. Journal of Business Research, 62(4), 509-516.

Dawar, N., \& Pillutla, M. M. (2000). Impact of product-harm crises on brand equity: The moderating role of consumer expectations. Journal of Marketing Research, 37(2), 215-226.

Di Gangi, P. M., \& Wasko, M. (2009). Open innovation through online communities. In Knowledge Management and Organizational Learning, 199-213. Springer, Boston, MA.

Di Gangi, P. M., \& Wasko, M. M. (2016). Social media engagement theory: Exploring the influence of user engagement on social media usage. Journal of Organizational and End User Computing, 28(2), 53-73.

Diamantini, C., Potena, D., \& Storti, E. (2013). A virtual mart for knowledge discovery in databases. Information Systems Frontiers, 15(3), 447-463.

Ding, M. C., Ho, C. W., \& Lii, Y. S. (2015). Is corporate reputation a double-edged sword? Relative effects of perceived justice in airline service recovery. International Journal of Economics and Business Research, 10(1), 1-17.

Drucker, P. (2012). The practice of management. Routledge.

Duan, L., Da, X., \& L. (2021). Data Analytics in Industry 4.0: A Survey. Information Systems Frontiers, 1-17.

Dutta, S., \& Pullig, C. (2011). Effectiveness of corporate responses to brand crises: The role of crisis type and response strategies. Journal of Business Research, 64(12), 1281-1287.

Dwivedi, Y. K., Ismagilova, E., Rana, N. P., \& Raman, R. (2021). Social media adoption, usage and impact in business-to-business (B2B) context: A state-of-the-art literature review. Information Systems Frontiers, 1-23.

Eguchi, K., \& Lavrenko, V. (2006). Sentiment retrieval using generative models. In Proceedings of the 2006 conference on empirical methods in Natural Language Processing, 345-354.

Elsbach, K. D., \& Bhattacharya, C. B. (2001). Defining who you are by what you're not: Organizational disidentification and the National Rifle Association. Organization Science, 12(4), 393-413.

Erat, P., Desouza, K. C., Schäfer-Jugel, A., \& Kurzawa, M. (2006). Business customer communities and knowledge sharing: exploratory study of critical issues. European Journal of Information Systems, 15(5), 511-524.

Farrokhi, A., Shirazi, F., Hajli, N., \& Tajvidi, M. (2020). Using artificial intelligence to detect crisis related to events: Decision making in B2B by artificial intelligence. Industrial Marketing Management, 91, 257-273.

Feng, J., Huang, S., \& Chen, C. (2020). Modeling user interaction with app-based reward system: A graphical model approach integrated with max-margin learning. Transportation Research Part C: Emerging Technologies, 120, 102814.

Forman, C., Ghose, A., \& Wiesenfeld, B. (2008). Examining the relationship between reviews and sales: The role of reviewer identity disclosure in electronic markets. Information Systems Research, 19(3), 291-313.

Fornell, C. G., \& Larcker, D. F. (1981). Evaluating structural equation models with unobservable variables and measurement error. Journal of Marketing Research, 18(1), 39-50.

Ghotbabadi, A. R., Feiz, S., \& Baharun, R. (2016). The relationship of customer perceived risk and customer satisfaction. Mediterranean Journal of Social Sciences, 7(1 S1), 161.

Giannakos, M. N., Mikalef, P., \& Pappas, I. O. (2021). Systematic Literature Review of E-Learning Capabilities to Enhance Organizational Learning. Information Systems Frontiers, 1-17.

Grewal, R., \& Tansuhaj, P. (2001). Building organizational capabilities for managing economic crisis: The role of market orientation and strategic flexibility. Journal of Marketing, 65(2), 67-80.

Grundy, M., \& Moxon, R. (2013). The effectiveness of airline crisis management on brand protection: A case study of British Airways. Journal of Air Transport Management, 28, 55-61.

Gudivada, V. N., Irfan, M. T., Fathi, E., \& Rao, D. L. (2016). Cognitive analytics: Going beyond big data analytics and machine learning. In Handbook of Statistics, 35, 169-205.

Guenther, M., \& Guenther, P. (2020). Is advertising an underappreciated driver of sales growth in B2B markets? Theoretical perspectives and empirical evidence. Industrial Marketing Management, 87, 76-89.

Gupta, A., Deokar, A., Iyer, L., Sharda, R., \& Schrader, D. (2018). Big data \& analytics for societal impact: Recent research and trends. Information Systems Frontiers, 20(2), 185-194.

Hair, J.F., Anderson, R.E., Tatham, R.L., \& Black, W.C. (2006). Multivariate Data Analysis, 6th edition Prentice Hall, New Jersey.

Hallikainen, H., Savimäki, E., \& Laukkanen, T. (2020). Fostering B2B sales with customer big data analytics. Industrial Marketing Management, 86, 90-98. 
Hausman, A., Noori, B., \& Salimi, M. H. (2005). A decision-support system for business-to-business marketing. Journal of Business \& Industrial Marketing, 20(4/5), 226-236.

Hemus, J., 2010. Accelerating Towards Crisis: A PR View of Toyota's Recall. Retrieved from: http://www.guardian.co.uk/business/ 2010/feb/09/prview-toyota-reputation-management. Accessed on 18th August 2020.

Herrmann, M. R., Brumby, D. P., Cheng, L., Gilbert, X. M., \& Oreszczyn, T. (2021). An empirical investigation of domestic energy data visualizations. International Journal of Human-Computer Studies, 152, 102660.

Hijjawi, G. S., \& Al-Shawabkeh, K. M. (2017). Impact of strategic agility on business continuity management (BCM): The moderating role of entrepreneurial alertness: An applied study in Jordanian insurance companies. International. Journal of Business and Management, 12(10). https://doi.org/10.5539/ijbm.v12n10p155

Hooper, D., Coughlan, J., \& Mullen, M. R. (2008). Structural equation modelling: Guidelines for determining model fit. Electronic Journal of Business Research Methods, 6(1), 53-60.

Hung, P. C., Chiu, D. K., Fung, W. W., Cheung, W. K., Wong, R., Choi, S. P., Kafeza, E., Kwok, J., Pun, J. C., \& Cheng, V. S. (2007). End-to-end privacy control in service outsourcing of human intensive processes: A multi-layered web service integration approach. Information Systems Frontiers, 9(1), 85-101.

Iabc, A. (2018). Reputation repair: The 5 stages of crisis recovery [Blog post]. Retrieved from https://www.iabc.com/reputationrepair-the-5-stages-of-crisis-recovery-2/. Accessed on 18th August 2020

Iannacci, F., Fearon, C., \& Pole, K. (2020). From acceptance to adaptive acceptance of social media policy change: A set-theoretic analysis of B2B SMEs. Information Systems Frontiers, 1-18.

Im, I., Kim, Y., \& Han, H. J. (2008). The effects of perceived risk and technology type on users' acceptance of technologies. Information \& Management, 45(1), 1-9.

Jeng, S. P. (2008). Effects of corporate reputations, relationships and competing suppliers' marketing programmes on customers' crossbuying intentions. The Service Industries Journal, 28(1), 15-26.

Jeng, S. P. (2011). The effect of corporate reputations on customer perceptions and cross-buying intentions. The Service Industries Journal, 31(6), 851-862.

Jensen, T. B., \& Aanestad, M. (2007). How Healthcare Professionals "Make Sense" of an Electronic Patient Record Adoption. Information Systems Management, 24(1), 29-42.

Jianying, Z. (2012). Crisis Management based on the Five Hypotheses proposed by Jack Welch. In Proceedings of the 2012 International Conference on Public Management, 217-221. Atlantis Press.

Johnson, M. S., Garbarino, E., \& Sivadas, E. (2006). Influences of customer differences of loyalty, perceived risk and category experience on customer satisfaction ratings. International Journal of Market Research, 48(5), 601-622.

Joinson, A. N. (2008). Looking at, looking up or keeping up with people? Motives and use of Facebook. In Proceedings of the SIGCHI conference on Human Factors in Computing Systems, $1027-1036$.

Joyce, A., \& Paquin, R. L. (2016). The triple layered business model canvas: A tool to design more sustainable business models. Journal of Cleaner Production, 135, 1474-1486.

Kaiser, C., Schlick, S., \& Bodendorf, F. (2011). Warning system for online market research-identifying critical situations in online opinion formation. Knowledge-Based Systems, 24(6), 824-836.

Kelley, B., \& Buchanan, J. (2017). The Lifecycle of a Washing Machine: Transforming the Customer Experience for a Home Appliance Manufacturer. In Ethnographic Praxis in Industry Conference Proceedings, 2017(1), 458-476.
Kettinger, W. J., \& Lee, C. C. (1994). Perceived Service Quality and User Satisfaction with the Information-Services Function. Decision Sciences, 25(5-6), 737-766.

Klein, J., \& Dawar, N. (2004). Corporate social responsibility and consumers' attributions and brand evaluations in a product-harm crisis. International Journal of Research in Marketing, 21(3), 203-217.

Kline, R. B. (2015). Principles and practice of structural equation modeling (4th edition). New York, USA: Guilford publications.

Knight F. R. \& Pretty P. L. (2001). Reputation \& Value the case of corporate catastrophes [report]. Retrieved from http://www. oxfordmetrica.com/public/CMS/Files/488/01RepComAIG.pdf. Accessed on 22nd August 2020,

Ku, L. W., Liang, Y. T., \& Chen, H. H. (2006). Opinion extraction, summarization and tracking in news and blog corpora. In AAAI spring symposium: Computational approaches to analyzing weblogs, 100107, 1-167.

Kushwaha, A. K., \& Kar, A. K. (2021). MarkBot - A Language Model-Driven Chatbot for Interactive Marketing in Post-Modern World. Information Systems Frontiers,https://doi.org/10.1007/ s10796-021-10184-y.

Leek, S., \& Christodoulides, G. (2011). A literature review and future agenda for b2b branding: Challenges of branding in a b2b context. Industrial Marketing Management, 40(6), 830-837.

Lei, J., Rao, Y., Li, Q., Quan, X., \& Wenyin, L. (2014). Towards building a social emotion detection system for online news. Future Generation Computer Systems, 37, 438-448.

Lemke, F., Clark, M., \& Wilson, H. (2011). Customer experience quality: an exploration in business and consumer contexts using repertory grid technique. Journal of the Academy of Marketing Science, 39(6), 846-869.

Lepenioti, K., Bousdekis, A., Apostolou, D., \& Mentzas, G. (2020). Prescriptive analytics: Literature review and research challenges. International Journal of Information Management, 50, 57-70.

Li, X., Peng, Q., Sun, Z., Chai, L., \& Wang, Y. (2017). Predicting social emotions from readers' perspective. IEEE Transactions on Affective Computing, 10(2), 255-264.

Lindgreen, A., Beverland, M. B., \& Farrelly, F. (2010). From strategy to tactics: Building, implementing, and managing brand equity in business markets. Industrial Marketing Management, 39(8), $1223-1225$.

Loebbecke, C. (2007). Use of innovative content integration information technology at the point of sale. European Journal of Information Systems, 16(3), 228-236.

London, M., \& Smither, J. W. (1999). Empowered self-development and continuous learning. Human Resource Management: Published in Cooperation with the School of Business Administration, The University of Michigan and in alliance with the Society of Human Resources Management, 38(1), 3-15.

Lopez-Nicolas, C., \& Molina-Castillo, F. J. (2008). Customer Knowledge Management and E-commerce: The role of customer perceived risk. International Journal of Information Management, 28(2), 102-113.

Luo, X., Zhang, J., \& Duan, W. (2013). Social media and firm equity value. Information Systems Research, 24(1), 146-163.

MacCallum, R. C., Browne, M. W., \& Sugawara, H. M. (1996). Power analysis and determination of sample size for covariance structure modeling. Psychological Methods, 1(2), 130.

Malhotra, N. K., Kim, S. S., \& Patil, A. (2006). Common method variance in IS research: A comparison of alternative approaches and a reanalysis of past research. Management Science, 52(12), $1865-1883$

Mäntymäki, M., Hyrynsalmi, S., \& Koskenvoima, A. (2020). How do small and medium-sized game companies use analytics? An attention-based view of game analytics. Information Systems Frontiers, 22(5), 1163-1178. 
Martin, J., Mortimer, G., \& Andrews, L. (2015). Re-examining online customer experience to include purchase frequency and perceived risk. Journal of Retailing and Consumer Services, 25, 81-95.

McLean, G. J. (2017). Investigating the online customer experiencea B2B perspective. Marketing Intelligence \& Planning., 35(5), 657-672.

Meyer, C., \& Schwager, A. (2007). Understanding customer experience. Harvard Business Review, 85(2), 116.

Mitchell, V. W. (1998). A role for consumer risk perceptions in grocery retailing. British Food Journal, 100(4), 171-183.

Morabito, V. (2014). Social Listening. In Trends and Challenges in Digital Business Innovation, 67-87. Springer, Cham.

Muzellec, L., Doogan, M., \& Lambkin, M. (2003). Corporate rebranding-an exploratory review. Irish Marketing Review, $16,31-40$.

Muzellec, L., Ronteau, S., \& Lambkin, M. (2015). Two-sided Internet platforms: A business model lifecycle perspective. Industrial Marketing Management, 45, 139-150.

Namisango, F., Kang, K., \& Beydoun, G. (2021). How the Structures Provided by Social Media Enable Collaborative Outcomes: A Study of Service Co-creation in Nonprofits. Information Systems Frontiers, 1-19.

Pace, S., Balboni, B., \& Gistri, G. (2017). The effects of social media on brand attitude and WOM during a brand crisis: Evidences from the Barilla case. Journal of Marketing Communications, 23(2), 135-148.

Parise, S., Guinan, P. J., \& Kafka, R. (2016). Solving the crisis of immediacy: How digital technology can transform the customer experience. Business Horizons, 59(4), 411-420.

Patterson, B. (1993). Crises impact on reputation management. The Public Relations Journal, 49(11), 48.

Pearson, C. M., \& Mitroff, I. I. (1993). From crisis prone to crisis prepared: A framework for crisis management. Academy of Management Perspectives, 7(1), 48-59.

Pfeffer, J., Zorbach, T., \& Carley, K. M. (2014). Understanding online firestorms: Negative word-of-mouth dynamics in social media networks. Journal of Marketing Communications, 20(1-2), $117-128$.

Podsakoff, P. M., MacKenzie, S. B., Lee, J. Y., \& Podsakoff, N. P. (2003). Common method biases in behavioral research: a critical review of the literature and recommended remedies. Journal of Applied Psychology, 88(5), 879.

Poria, S., Cambria, E., \& Gelbukh, A. (2015). Deep convolutional neural network textual features and multiple kernel learning for utterance-level multimodal sentiment analysis. In Proceedings of the 2015 conference on empirical methods in natural language processing, 2539-2544.

Poria, S., Cambria, E., Hazarika, D., \& Vij, P. (2016). A deeper look into sarcastic tweets using deep convolutional neural networks. In Proceedings of the 26th International Conference on Computational Linguistics, 1601-1612.

Poria, S., Gelbukh, A., Hussain, A., Howard, N., Das, D., \& Bandyopadhyay, S. (2013). Enhanced SenticNet with affective labels for concept-based opinion mining. IEEE Intelligent Systems, 28(2), 31-38.

Porra, J. (2000). Electronic commerce Internet strategies and business models-A survey. Information Systems Frontiers, 1(4), 389-399.

Prahalad, C. K., \& Ramaswamy, V. (2004). The future of competition: Co-creating unique value with customers. Boston, MA: Harvard Business School Press.

Püschel, L. C., Röglinger, M., \& Schlott, H. (2016). What's in a Smart Thing? Development of a Multi-layer Taxonomy. In ICIS, 4801, $1-19$.

Quan, X., Wang, Q., Zhang, Y., Si, L., \& Wenyin, L. (2015). Latent discriminative models for social emotion detection with emotional dependency. ACM Transactions on Information Systems, 34(1), $1-19$.

Rabhi, F. A., Bandara, M., Lu, K., \& Dewan, S. (2021). Design of an innovative IT platform for analytics knowledge management. Future Generation Computer Systems, 116, 209-219.

Rao, Y. (2015). Contextual sentiment topic model for adaptive social emotion classification. IEEE Intelligent Systems, 31(1), 41-47.

Rao, Y., Li, Q., Mao, X., \& Wenyin, L. (2014a). Sentiment topic models for social emotion mining. Information Sciences, 266, 90-100.

Rao, Y., Li, Q., Wenyin, L., Wu, Q., \& Quan, X. (2014b). Affective topic model for social emotion detection. Neural Networks, $58,29-37$.

Rawson, A., Duncan, E., \& Jones, C. (2013). The truth about customer experience. Harvard Business Review, 91(9), 90-98.

Ruhl, K. (2004). Qualitative Research Practice. A Guide for Social Science Students and Researchers. Historical Social Research, 29(4), 171-177.

Ruppel, C., \& Einwiller, S. (2021). Pleasant hostility: Disidentified consumers' emotional and behavioral reactions to a brand crisis. Journal of Consumer Behaviour, 20(1), 186-200.

Sahebjamnia, N., Torabi, S. A., \& Mansouri, S. A. (2015). Integrated business continuity and disaster recovery planning: Towards organizational resilience. European Journal of Operational Research, 242(1), 261-273.

Sasidhar, T. T., Premjith, B., \& Soman, K. P. (2020). Emotion Detection in Hinglish (Hindi+ English) Code-Mixed Social Media Text. Procedia Computer Science, 171, 1346-1352.

Schivinski, B., \& Dabrowski, D. (2016). The effect of social media communication on consumer perceptions of brands. Journal of Marketing Communications, 22(2), 189-214.

Shami, N. S., Yang, J., Panc, L., Dugan, C., Ratchford, T., Rasmussen, J. C., Assogba, Y., Steier, T., Soule, T., Lupushor, S., Geyer, W., Guy, I. \& Geyer, W. (2014). Understanding employee social media chatter with enterprise social pulse. In Proceedings of the 17th ACM conference on Computer supported cooperative work \& social computing, 379-392.

Shao, G., Shin, S. J., \& Jain, S. (2014). Data analytics using simulation for smart manufacturing. In Proceedings of the Winter Simulation Conference 2014, 2192-2203. IEEE.

Sikora, R. T., \& Chauhan, K. (2012). Estimating sequential bias in online reviews: a Kalman filtering approach. Knowledge-Based Systems, 27, 314-321.

Siomkos, G. J., \& Kurzbard, G. (1994). The hidden crisis in product-harm crisis management. European Journal of Marketing, $28(2), 30-41$.

Smith, K. S., McCreadie, R., Macdonald, C., \& Ounis, I. (2018). Regional sentiment bias in social media reporting during crises. Information Systems Frontiers, 20(5), 1013-1025.

Song, J. H., \& Zinkhan, G. M. (2008). Determinants of perceived web site interactivity. Journal of Marketing, 72(2), 99-113.

Song, S. K., Jeong, D. H., Kim, J., Hwang, M., Gim, J., \& Jung, H. (2014). Research advising system based on prescriptive analytics. In Future Information Technology, 569-574. Springer, Berlin, Heidelberg.

Stewart, M. C., \& Arnold, C. L. (2018). Defining social listening: Recognizing an emerging dimension of listening. International Journal of Listening, 32(2), 85-100.

Stewart, M. C., Atilano, M., \& Arnold, C. L. (2017). Improving customer relations with social listening: A case study of an American academic library. International Journal of Customer Relationship Marketing and Management, 8(1), 49-63.

Stone, R. N., \& Grønhaug, K. (1993). Perceived risk: Further considerations for the marketing discipline. European Journal of Marketing, 27(3), 39-50. 
Sun, J. (2020). Ubiquitous computing capabilities and user-system interaction readiness: An activity perspective. Information Systems Frontiers, 22(1), 259-271.

Tam, J. L. M. (2012). The moderating role of perceived risk in loyalty intentions: an investigation in a service context. Marketing Intelligence \& Planning, 30(1), 33-52.

Tanaka, J. S., \& Huba, G. J. (1989). A general coefficient of determination for covariance structure models under arbitrary GLS estimation. British Journal of Mathematical and Statistical Psychology, 42(2), 233-239.

Tang, D., Zhang, Z., He, Y., Lin, C., \& Zhou, D. (2019). Hidden topic-emotion transition model for multi-level social emotion detection. Knowledge-Based Systems, 164, 426-435.

Trivedi, J. (2019). Examining the customer experience of using banking Chatbots and its impact on brand love: the moderating role of perceived risk. Journal of Internet Commerce, 18(1), 91-111.

Truyen, T. T., Phung, D. Q., \& Venkatesh, S. (2014). Preference networks: Probabilistic models for recommendation systems. arXiv preprint arXiv: 1407.5764.

Tucker, L. R., \& Lewis, C. (1973). A reliability coefficient for maximum likelihood factor analysis. Psychometrika, 38(1), 1-10.

Utz, S., Schultz, F., \& Glocka, S. (2013). Crisis communication online: How medium, crisis type and emotions affected public reactions in the Fukushima Daiichi nuclear disaster. Public Relations Review, 39(1), 40-46.

Vargo, S. L., \& Lusch, R. F. (2006). Service-dominant logic: What it is, what it is not, what it might be. In The Service-Dominant Logic of Marketing (pp. 61-74). Routledge.

Vargo, S. L., \& Lusch, R. F. (2011). It's all B2B ... and beyond: Toward a systems perspective of the market. Industrial Marketing Management, 40(2), 181-187.

Wang, Q., Wu, O., Hu, W., Yang, J., \& Li, W. (2011). Ranking social emotions by learning listwise preference. In The First Asian Conference on Pattern Recognition (pp. 164-168). IEEE.

Wang, Y., Rod, M., Deng, Q., \& Ji, S. (2020). Exploiting business networks in the age of social media: the use and integration of social media analytics in B2B marketing. Journal of Business \& Industrial Marketing.https://doi.org/10.1108/JBIM-05-2019-0173.

Wang, Y., Yin, G., Cai, Z., Dong, Y., \& Dong, H. (2015). A trust-based probabilistic recommendation model for social networks. Journal of Network and Computer Applications, 55, 59-67.

Wells, P. (2018). Degrowth and techno-business model innovation: The case of Riversimple. Journal of Cleaner Production, 197, $1704-1710$

Wiboonrat, M. (2008). An empirical IT contingency planning model for disaster recovery strategy selection. In 2008 IEEE International Engineering Management Conference, 1-5.

Wiboonrat, M., \& Kosavisutte, K. (2008). Optimization strategy for disaster recovery. In 2008 4th IEEE International Conference on Management of Innovation and Technology, 675-680.

Wixom, B. H., \& Todd, P. A. (2005). A theoretical integration of user satisfaction and technology acceptance. Information Systems Research, 16(1), 85-102.

Wolter, J. S., Brach, S., Cronin Jr., J. J., \& Bonn, M. (2016). Symbolic drivers of consumer-brand identification and disidentification. Journal of Business Research, 69(2), 785-793.

Xie, Z., Liu, G., Qu, J., Wu, J., \& Li, H. (2021). Identifying Structural Holes for Sentiment Classification. Information Systems Frontiers. https://doi.org/10.1007/s10796-021-10185-x

Xu, K., \& Li, W. (2013). An ethical stakeholder approach to crisis communication: A case study of Foxconn's 2010 employee suicide crisis. Journal of Business Ethics, 117(2), 371-386.

Xu, Y., Wang, L., Xu, B., Jiang, W., Deng, C., Ji, F., \& Xu, X. (2019). An information integration and transmission model of multi-source data for product quality and safety. Information Systems Frontiers, 21(1), 191-212.

Yannopoulou, N., Koronis, E., \& Elliott, R. (2011). Media amplification of a brand crisis and its affect on brand trust. Journal of Marketing Management, 27(5-6), 530-546.

Yuan, D., Lin, Z., Filieri, R., Liu, R., \& Zheng, M. (2020). Managing the product-harm crisis in the digital era: The role of consumer online brand community engagement. Journal of Business Research, 115, 38-47.

Zhang, J., Jiang, Y., Shabbir, R., \& Zhu, M. (2016). How brand orientation impacts B2B service brand equity? An empirical study among Chinese firms. Journal of Business \& Industrial Marketing, 31(1), 83-98.

Zhang, Z., \& Gupta, B. B. (2018). Social media security and trustworthiness: overview and new direction. Future Generation Computer Systems, 86, 914-925.

Zolbanin, H. M., Delen, D., Crosby, D., \& Wright, D. (2019). A predictive analytics-based decision support system for drug courts. Information Systems Frontiers, 1-20.

Zolkiewski, J., Story, V., Burton, J., Chan, P., Gomes, A., Hunter-Jones, P., O’Malley, L., Peters, L., Raddats, C., \& Robinson, W. (2017). Strategic B2B customer experience management: the importance of outcomes-based measures. Journal of Services Marketing, $31(2), 172-184$.

Zoric, J., \& Braek, R. (2011). Scenario based techno-business analysis of service platforms and their service portfolios. Telecommunication Systems, 46(2), 95-116.

Zott, C., \& Amit, R. (2010). Business model design: An activity system perspective. Long Range Planning, 43(2-3), 216-226.

Zott, C., Amit, R., \& Massa, L. (2011). The business model: recent developments and future research. Journal of Management, 37(4), 1019-1042.

Zutshi, A., \& Grilo, A. (2019). The emergence of digital platforms: A conceptual platform architecture and impact on industrial engineering. Computers \& Industrial Engineering, 136, 546-555.

Publisher's Note Springer Nature remains neutral with regard to jurisdictional claims in published maps and institutional affiliations.

Rajat Kumar Behera is an Associate Professor in the School of Computer Engineering at Kalinga Institute of Industrial Technology (KIIT) Deemed to be University. His current research area includes Data Science \& Business Analytics, Technology Adoption, Ethics \& Technology and Software Engineering. He has published research articles in leading journals, conference proceedings and holds professional designations including PMP, ITIL and Six Sigma Green Belt. He worked in IBM India before joining academics. He is also a member of Computer Society of India (CSI).

Pradip Kumar Bala , professor in the area of Information Systems \& Business Analytics at Indian Institute of Management (IIM) Ranchi, received his B.Tech., M.Tech. and Ph.D. from Indian Institute of Technology (IIT) Kharagpur in 1993, 1999 and 2009 respectively. He worked in Tata Steel before joining academics. He also worked in Xavier Institute of Management Bhubaneswar and IIT, Roorkee before joining IIM Ranchi in 2012. His teaching and research areas include text mining \& NLP, recommender systems, data mining applications, data mining and NLP algorithms, social media analytics and marketing analytics. He has conducted many training programmes in business analytics \& business intelligence. He has published more than 100 research papers in reputed international journals, conference proceedings and book chapters. He is also a member of the International Association of Engineers (IAENG). He served as Dean (Academics), 
Chairperson, Post-Graduate Programmes, Chairperson, Doctoral Programme \& Research, and Member of Board of Governors of IIM Ranchi.

Nripendra P. Rana is a Professor in Marketing at the College of Business and Economics at Qatar University, Doha, Qatar. His current research interests focus primarily on adoption and diffusion of emerging ICTs, e-commerce, m-commerce, e-government and digital and social media marketing. He has published more than 200 papers in a range of leading academic journals, conference proceedings, books etc. He has co-edited five books on digital and social media marketing, emerging markets and supply and operations management. He has also co-edited special issues, organised tracks, mini-tracks and panels in leading conferences. He is a Chief Editor of International Journal of Electronic Government Research and an Associate Editor of International Journal of Information Management. He is a Senior Fellow of the Higher Education Academy (SFHEA) in the UK. He is also a Distinguished Visiting Professor at University of Johannesburg, South Africa.

Hatice Kizgin is Associate Professor in Marketing in the faculty of Behavioural, Management and Social Sciences, University of Twente, Netherlands. Hatice has published articles in leading academic journals and has presented her research in some of the prominent international conferences of marketing. She is the Co-editor of the book "Advances in Theory and Practice of Digital Marketing", Springer Publications. In addition she has co-edited special issues published by Journal of Retailing and Consumer Services, Journal of Consumer Behavior and International Journal of Information Management. Hatice holds the position of Deputy Chair at Academy of Marketing Special Interest Group: Digital Marketing and Data Analytics https://www.academyofm arketing.org/sigs/digital-marketing-sig/. Hatice is board member of Assadaqaat Community Finance (ACF) designed to address financial and social exclusion, financial inequality and eradicate poverty. 